\title{
NATURALEZA SINTÁCTICA DE LOS ENUNCIADOS TEXTUALES EN EL DISCURSO ESCRITO
}

\author{
THE SYNTACTIC NATURE OF UTTERANCES IN WRITTEN DISCOURSE
}

\author{
José M. Bustos GisBerT \\ Universidad de Salamanca \\ jbustos@usal.es
}

Recibido: $26 / 07 / 2017$

Aceptado: 20/09/2017

\begin{abstract}
Resumen
Este artículo describe la naturaleza sintáctica de los enunciados en el discurso escrito a partir de un corpus de 369 textos. Se maneja como variable de análisis su naturaleza narrativa, descriptiva, expositiva o instructiva. Primero se evalúa la extensión de los enunciados, unidades textuales mínimas, y se establecen las tendencias en lo referido a longitud mínima, máxima y promedio. En segundo lugar, se analiza el rendimiento de las unidades sintácticas oracionales y no oracionales. Dentro las primeras, se estudia el aprovechamiento de las oraciones simples y compuestas, en las que se valoran las diferentes alternativas de configuración, los procedimientos de incrustación sintáctica y el rendimiento de las construcciones coordinadas. Finalmente, se centra en la naturaleza de las predicaciones verbales dentro de los enunciados. Para ello se valora el número de predicaciones por enunciado y el aprovechamiento de las formas conjugadas, las no personales y las perifrásticas

PALABRAS CLAVE: Unidades textuales, enunciado, sintaxis del discurso escrito, texto escrito, tipología textual.
\end{abstract}

\begin{abstract}
This article describes the syntactic nature of utterances in written discourse extracted from a corpus of 369 texts. For this purpose, the narrative, descriptive, expository or instructive nature of texts is handled as an analysis variable. First, the length of the phrases is evaluated and the tendencies in terms of the minimum, maximum and average number of words are established. Second, we analyze the performance of sentence and non-sentence syntactic units. In the first, we study the use of simple and compound sentences, in which we evaluate the different structural alternatives, the syntactic embedding procedures and the performance of the coordinated constructions. Finally, the study focuses on the nature of verbal predicates within utterances. In order to do this, we study the number of predicates per phrase and the use of conjugated, non-personal and periphrastic forms.

KEYWORDS: Textual units, utterance, syntax of written speech, written text, textual typology.
\end{abstract}

Para citar este artículo / To cite this article: Bustos Gisbert, José M. (2017). Naturaleza sintáctica de los enunciados textuales en el discurso escrito. ELUA, 31: 67-95. doi: 10.14198/ELUA2017.31.04

Enlace / Link: http://dx.doi.org/10.14198/ELUA2017.31.04 


\section{INTRODUCCIÓN}

Partimos en este trabajo de una concepción del enunciado como la unidad mínima de construcción discursiva ${ }^{1}$. Como bien afirma Fuentes (2014: 138), “construimos los mensajes con oraciones y palabras, pero consideradas desde la producción generan enunciados y textos". Según ella, existen dos sistemas de unidades según analicemos la comunicación desde el sistema lingüístico (estudiaremos oraciones, sintagmas, lexías, morfemas...) o desde una perspectiva pragmática del uso: en tal caso el objeto de estudio serán el texto, la secuencia, el párrafo y el enunciado. Es necesario, pues, deslindar dos unidades correspondientes a niveles de análisis diferentes como son la oración y el enunciado; superaremos así percepciones erróneas en las que el texto se define como unidad superior a la oración. Efectivamente, no nos comunicamos con oraciones sino con enunciados. Otra cosa es que el enunciado se plasme en oraciones o en otras unidades gramaticales.

El enunciado se ha estudiado de manera recurrente en nuestra tradición lingüística y muy especialmente en la escuela funcionalista. Gutiérrez Ordóñez (1997) postula como bases del enunciado la independencia sintáctica, la autosuficiencia semántica y la posibilidad de identificar en él formulación (equivalente al modus de la gramática tradicional) y esquema (estructura combinatoria). Fuentes (2009) completa la descripción destacando su naturaleza discursiva: la oración es una estructura abstracta y no realizada, y el enunciado es la unidad mínima de comunicación en una situación concreta. Es un acto realizado y dependiente del contexto: la enunciación, la modalidad, las marcas interactivas... son rasgos propios de los enunciados. Son las unidades de construcción discursiva más pequeñas y tienen su correlato formal en oraciones o en sintagmas; en definitiva, en cualquier unidad que, como afirma Gutiérrez Ordóñez, exhiba independencia sintáctica y autosuficiencia semántica. Fuentes (2014) distingue cuatro tipos de enunciados: los canónicos responderían plenamente a los rasgos indicados antes. En los parentéticos, un enunciado interrumpe y se incrusta en otro; en la lengua escrita se marcan mediante la puntación merced al uso de signos como los paréntesis o los guiones. Los colaborativos estarían construidos por dos enunciadores distintos, por lo que serían propios y exclusivos del discurso oral. Por último, en los suspendidos el acto de habla se formaliza con una estructura sintáctica inacabada que se puede completar desde el contexto; en muchos casos, el uso de los puntos suspensivos desvelaría en la lengua escrita esta naturaleza.

El enunciado aporta al menos una información temática y otra remática, y establece relaciones de coherencia lineal con otras unidades de similar naturaleza: según Pastor (2008) los enunciados avanzan combinando temas y remas que dosifican la información. Se convierten en eslabones de la cadena informativa que configuran los párrafos. Ahora bien, pueden incorporar más de un tema y un rema; sin embargo, a medida que el número de relaciones dentro del enunciado crece, se irá alejando de esa percepción de unidad informativa mínima. En cualquier caso, el gusto por enunciados más o menos complejos en términos de su configuración temático/remática se convierte a menudo en una elección estilística.

1 Volvemos en este epígrafe a Bustos Gisbert (2013a: 63-76), donde hemos desarrollado a fondo el concepto de enunciado en el marco del texto escrito. 
Los límites de estas unidades están vinculados a la capacidad de procesamiento informativo de la que dispone el ser humano. Los enunciados transmiten una información que se almacena de manera provisional y literal en la memoria a corto plazo. Solo en el momento en el que se llega al final del enunciado, la información se transforma y se transfiere a la memoria a largo plazo en una forma no literal. Como apuntan Berko y Bernstein (2001), en esta no se recupera la literalidad de los mensajes sino su esencia conceptual: se recuerda lo que significa el enunciado y se olvida la forma salvo que sea relevante por sí misma: en un poema, en una adivinanza, en un trabalenguas, etc. Y cuanto antes se genera tal imagen conceptual, antes se desvanece la imagen literal del mensaje. No obstante, la capacidad humana para retener palabras en la memoria a corto plazo no es limitada, sino limitadísima: una palabra desconocida o inesperada puede complicar el procesamiento y la regulación de la memoria. Hasta el punto de que no es posible recordar aquello que no se entiende. Al mismo tiempo, apuntan que el número de cláusulas que tiene un enunciado afecta al tiempo de procesamiento: la resolución sintáctica es necesaria para poner en marchar el proceso de comprensión. El problema, pues, no es tan solo la longitud del enunciado sino también la calidad y la configuración formal de la información incluida. Como apunta Pinker (1995), si se segmenta con incisos, si se organiza en estructuras sintácticas reiterativas, si se construye sobre la base de unidades informativas dispersas o si no se respeta el equilibrio entre lo temático y lo remático, se dificultará la transferencia de la información desde la memoria a corto plazo al entendimiento.

El objetivo central de este trabajo será analizar cómo se configuran sintácticamente los enunciados. A partir de las posibilidades teóricas que facilita el sistema lingüístico, nos interesa desentrañar cuáles son los patrones formales más productivos. Y para llevar a cabo nuestra labor partiremos de un corpus de trabajo tomado de Corputrad ${ }^{2}$. Está compuesto por 369 textos de entre 400 y 450 palabras escritos durante 2012/2013 y 2013/2014. Todos ellos formaron parte de la evaluación del curso y fueron redactados en el aula; con el fin de garantizar que se trataba de autores competentes en expresión escrita, solo se han valorado aquellos ejercicios que obtuvieron una nota igual o superior a 6 , en una escala de 0 a 10, y que fueron escritos por estudiantes cuya lengua materna es el castellano. En el caso de los textos narrativos los informantes tuvieron que redactar una noticia periodística ${ }^{3}$. En las descripciones se plantearon dos tareas: una referida a una persona y otra centrada en su vivienda habitual. Para los textos instructivos se les exigió escribir sendos manuales de instrucciones: uno para embarazadas y otro para el cuidado de un recién nacido. Finalmente, los expositivos fueron dos textos de opinión. El corpus se resume de la siguiente manera ${ }^{4}$ :

2 Corputrad es un corpus de escritos originales redactados en español por estudiantes de primer curso del Grado en Traducción e Interpretación de la Universidad de Salamanca. En la actualidad reúne más de 4.500 textos escritos redactados entre 2006 y 2014 correspondientes a 500 informantes distintos y acumula más de dos millones y medio de palabras. La fiabilidad del corpus está justificada en Bustos Gisbert (2013b).

3 Se les daba una serie de 9 palabras que necesariamente tenían que incluir en el texto y que habían sido sacadas de una noticia real. A modo ilustrativo, en uno de ellos las palabras eran "envenenadora, indulto, hormigas, hospital, sentencia, desenlace, perdonada, postre y atenuante”. Fuente: http://www.lavanguardia.com/hemeroteca/20140519/54406526360/ pilar-prades-envenenamientos-homicidios-asesinatos-garrote-vil-ejecuciones-mujeres-espana-valencia.html

4 El número de textos narrativos es el menor porque se trata de la primera prueba evaluada realizada en el curso, por lo que las calificaciones suelen ser más bajas en tanto que los informantes apenas han recibido instrucción específica en expresión escrita. 


\begin{tabular}{|lrrrrrr|}
\multicolumn{1}{ll}{} & Textos & Palabras & Textos & Palabras & Textos & Palabras \\
\multicolumn{1}{l|}{$12 / 13$} & $12 / 13$ & $13 / 14$ & $13 / 14$ & Total & Total \\
\hline Narrativo & 38 & 12.285 & 35 & 13.369 & 73 & 25.654 \\
Descriptivo & 48 & 19.539 & 54 & 23.731 & 102 & 43.270 \\
Instructivo & 40 & 16.175 & 48 & 22.751 & 88 & 38.926 \\
Expositivo & 49 & 19.552 & 57 & 25.120 & 106 & 44.672 \\
& & & & & & \\
TOTAL & 175 & 67.551 & 194 & 84.971 & 369 & 152.522 \\
\hline
\end{tabular}

Cuadro 1. Corpus utilizado.

En una investigación de esta naturaleza se debe comenzar por segmentar los textos analizados en los enunciados que los componen. El procedimiento ya lo hemos descrito en trabajos anteriores y se efectúa desde la puntuación (Bustos Gisbert, 2013a). En opinión de De Beaugrande (1984), esta es el subsistema discursivo destinado a orientar la lectura y evidenciar las intenciones del autor: aun cuando la forma de puntuar no es en absoluto uniforme, marca unidades y subunidades textuales y, con ello, fija jerarquías y establece prioridades. Ferreiro (1996) defiende que la puntuación aporta marcas que guían la interpretación; por ello su uso se realiza a menudo desde una perspectiva retórica, asociada a las intenciones específicas del autor. Asimismo, afirma que las marcas de puntuación son de naturaleza heterogénea: algunas, como las interrogaciones y las exclamaciones, tienen valor suprasegmental; pero esto no ocurre con todas. De hecho, la mayor parte de los signos nada tienen que ver con la prosodia. Con ellos se fijan las unidades textuales de procesamiento informativo. Figueras (1999 y 2001) ha profundizado muy acertadamente en esta dirección: en su opinión, los signos dan información procedimental para procesar la información textual: cada signo se asociaría a una unidad de procesamiento. Esta percepción es la misma que la que alumbra la propuesta de la Real Academia Española en su Ortografía de 2010: "Los signos de puntuación (...) organizan el discurso para facilitar su comprensión" (p. 282) y su función será fijar los límites de las unidades lingüísticas, la modalidad de los enunciados (en el caso de los signos de interrogación, exclamación y, en algunos casos, los puntos suspensivos) o indicar la omisión de la parte de un enunciado. Roselló (2010) aporta un estudio imprescindible para comprender la función discursiva de la puntuación. Es en el texto escrito donde "esas señales despliegan toda su funcionalidad: ayudan a dotar de cohesión y coherencia al discurso, distribuyen y jerarquizan la información, marcan los cambios de ritmo de la prosa, adquieren diversas funciones según la intención o el tipo de texto, etc." (Roselló, 2010: 373).

Por tanto, parece posible afirmar que la puntuación cumple un papel esencial en el momento de fijar los límites de los enunciados en los textos de naturaleza escrita. Estos están identificados por aquellos signos que indican el final de períodos sintácticamente independientes: el punto y seguido, el punto y aparte, casi siempre el punto y coma, y en ocasiones los dos puntos (Bustos Gisbert 2013b). Asociamos al punto y aparte y al punto y seguido los signos de admiración e interrogación siempre que no vayan seguidos de una coma, y también los puntos suspensivos en los casos en los que estos pueden ser sustituidos por un punto. Del mismo modo, el punto y coma solo indica final de enunciado si puede ser conmutado por un punto y seguido. Los dos puntos indican fin de enunciado cuando 
son conmutables por un punto o por un punto y coma. Ello ocurre si fijan una relación de causa, efecto u oposición. También cuando hay una relación reformulativa que implica la aparición de un elemento anticipador antes de los dos puntos y la unidad siguiente presenta un concepto completo interpretable de manera independiente. Por la misma razón, indica final de enunciado cuando acompaña a títulos y epígrafes. Sin embargo, los dos puntos no indican fin de enunciado si no son sustituibles por un punto o un punto y coma. Así sucede cuando se construye una reformulación por vía de un concepto incompleto no interpretable de manera aislada. Ocurre de manera evidente cuando se reformula por vía de una enumeración simple. Tampoco cuando introduce una cita literal ni cuando se usa en lugar de la coma después de un conector.

Con el objeto de evitar desviaciones en el análisis se han corregido en el corpus los errores flagrantes referidos a la puntuación fuerte. Como resultado de todas las correcciones aplicadas, en 102 ocasiones hemos dividido un enunciado en dos y en una ocasión en tres. En dos casos hemos unido dos enunciados. Así y todo, debemos destacar que las correcciones solo han afectado al 1,12\% de los enunciados; tal hecho demuestra un elevado nivel de competencia por parte de los informantes en lo referido al uso de la puntuación, lo que justifica usar la unidad enunciado como base del análisis. Una vez realizados todos los ajustes, los textos del corpus se han segmentado en enunciados con arreglo a la puntuación para facilitar su interpretación sintáctica. Los datos disponibles para el análisis son estos:

\begin{tabular}{|l|r|r|r|}
\multicolumn{1}{c}{ Textos } & Palabras & Enunciados \\
\hline Narrativo & 73 & 25.654 & 1.267 \\
Descriptivo & 102 & 43.270 & 2.807 \\
Instructivo & 88 & 38.926 & 2.855 \\
Expositivo & 106 & 44.672 & 2.482 \\
& & & \\
TOTAL & 369 & 152.522 & 9.411 \\
\hline
\end{tabular}

Cuadro 2. Textos y enunciados.

\section{EXTENSIÓN DE LOS ENUNCIADOS}

2.1. Para el estudio de la extensión de los enunciados consideramos como base del análisis la unidad palabra sin establecer distinciones entre llenas y vacías ni tampoco desde su naturaleza morfológica. Un primer análisis nos aporta los siguientes resultados:

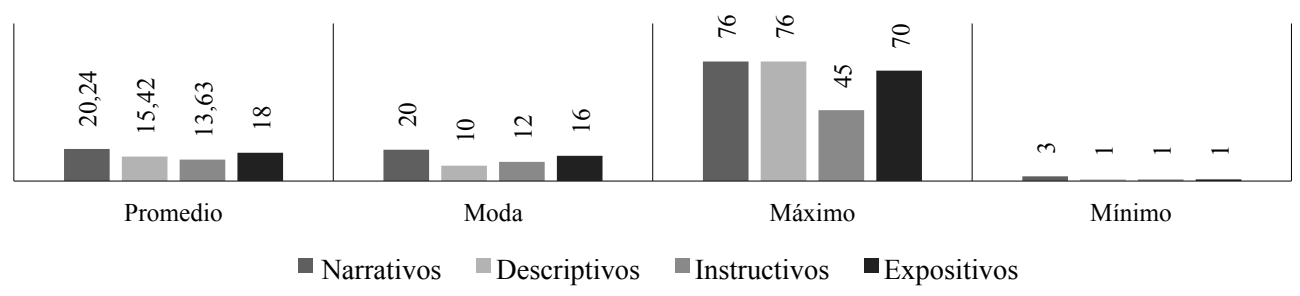

Cuadro 3. Extensión de enunciados. 
Los enunciados más cortos son de una sola palabra excepto en las narraciones, donde el mínimo se encuentra en tres. En cambio, la extensión máxima fluctúa bastante: es algo menor en los expositivos y desciende un $25 \%$ en los textos instructivos, en los que la extensión máxima es de 45. Sin embargo, en los textos narrativos y los descriptivos se han identificados ejemplos de 76 palabras ${ }^{5}$ :

1. Se estima que los daños materiales ascienden a cientos de millones de dólares, por lo que el gobierno ha solicitado la ayuda internacional para el abastecimiento de los materiales necesarios para la reconstrucción de infraestructuras, así como de bienes de primera necesidad, ya que un día después del desastre, numerosos supermercados y gasolineras se han quedado sin suministros, vendidos a personas que todavía luchan por sobrevivir, pero con un futuro menos halagüeño que la semana pasada $(\mathrm{N})$.

Por lo que afecta al promedio de extensión observamos en primer lugar que los enunciados narrativos y expositivos tienden a ser llamativamente más largos que los descriptivos y los instructivos, que resultan ser entre un $25 \%$ y un $30 \%$ más cortos. Sin embargo, esa distribución en dos grupos no se verifica cuando nos fijamos en la moda, referida a qué extensión es la más frecuente. Las cifras coinciden con las del promedio en el caso de los narrativos, pero desciende en los expositivos, en los instructivos y muy especialmente en los descriptivos. Esa falta de correlación entre promedio y moda nos invita a desagregrar los datos en sectores de extensión. Para ello, estableceremos franjas de enunciados que crecen de cinco en cinco palabras. Veamos cómo se distribuyen en los distintos bloques:

\begin{tabular}{|c|c|c|c|c|c|c|c|c|c|c|}
\hline & $0-5$ & $6-10$ & $11-15$ & $16-20$ & $21-25$ & $26-30$ & $31-35$ & $36-40$ & $41-45$ & $46+$ \\
\hline Narrativos & $2,05 \%$ & $11,21 \%$ & $19,49 \%$ & $22,26 \%$ & $19,57 \%$ & $13,26 \%$ & $7,18 \%$ & $3,08 \%$ & $1,18 \%$ & $0,71 \%$ \\
\hline Descriptivos & $5,02 \%$ & $22,52 \%$ & $27,25 \%$ & $23,76 \%$ & $12,61 \%$ & $5,88 \%$ & $2,00 \%$ & $0,50 \%$ & $0,29 \%$ & $0,18 \%$ \\
\hline - Instructivos & $6,44 \%$ & $26,80 \%$ & $32,75 \%$ & $20,49 \%$ & $9,56 \%$ & $3,19 \%$ & $0,67 \%$ & $0,07 \%$ & $0,04 \%$ & $0,00 \%$ \\
\hline Expositivos & $5,40 \%$ & $15,19 \%$ & $20,71 \%$ & $22,68 \%$ & $17,85 \%$ & $9,99 \%$ & $5,40 \%$ & $1,73 \%$ & $0,40 \%$ & $0,64 \%$ \\
\hline
\end{tabular}

Cuadro 4. Distribución de enunciados por franjas de palabras.

Asumiremos como relevante una frecuencia de uso igual o superior al 10\% a la hora de evaluar la extensión de enunciados. Desde esa consideración se puede identificar para cada grupo de textos una franja de máximo rendimiento, que da cuenta de más del $80 \%$ de los enunciados en cada modo del discurso estudiado. Así, en narrativos y expositivos, oscila entre 6 y 30 palabras: en los primeros, esa franja suma el 85,79\% de los casos; y en los segundos, el $86,42 \%$; por su parte, en los descriptivos la mayor frecuencia está entre 6 y 25 , y acumula un $86,14 \%$; finalmente, los enunciados más breves serían los instructivos, en los que el $80 \%$ se ubica entre 6 y 20 palabras.

5 Al final de cada ejemplo incluimos entre paréntesis una indicación acerca de si se trata de un enunciado narrativo, descriptivo, expositivo o instructivo con la inicial correspondiente a cada opción discursiva. 
En segundo lugar, cabe hablar de una longitud preferencial, que incluiría las tres franjas más empleadas en cada tipo textual. En narrativos y expositivos se situaría en $11 / 25$ palabras $(61,33 \%$ y $61,2 \%$ del total respectivamente), mientras que en descriptivos e instructivos desciende a $6 / 20(73,53 \%$ y $80,04 \%$ respectivamente).

Por último, cabe destacar que la extensión prototípica se ubicaría en el rango de 16 a 20 palabras: es la única franja en la que se supera el $20 \%$ de frecuencia en los cuatro modos del discurso.

2.2. El enunciado narrativo es el más largo y el más diverso en términos cuantitativos:

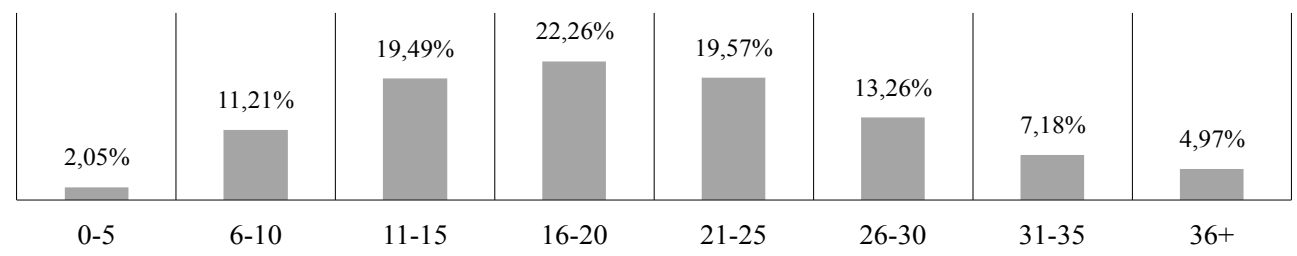

Cuadro 5. Extensión de los enunciados narrativos.

En cinco franjas se identifica una frecuencia superior al 10\%. De ellas, las tres centrales, correspondientes a 11-25, exhiben un porcentaje de uso en torno al 20\%. A su vez, otro $20 \%$ de los ejemplos consignados oscilan entre 26 y 35 palabras. Son, pues, cinco franjas de una frecuencia muy similar, lo que nos permite afirmar que, en este modo del discurso, la longitud de los enunciados se reparte de manera razonablemente uniforme entre 11 y 35 palabras.

Los enunciados más infrecuentes son de 10 o menos palabras (13\%) o de 36 o más palabras. Si nos fijamos en estos últimos, observamos que su frecuencia casi dobla el porcentaje de los de esa misma longitud en los textos expositivos, que son a su vez los siguientes en extensión. Tal hecho confirmaría que se trata del modo del discurso donde los enunciados tienden a ser más largos.

2.3. Por lo que afecta a las secuencias expositivas, hay, como en las narrativas, cinco franjas por encima del $10 \%$ de aparición y las tres más usadas también están entre 11 y 25 :

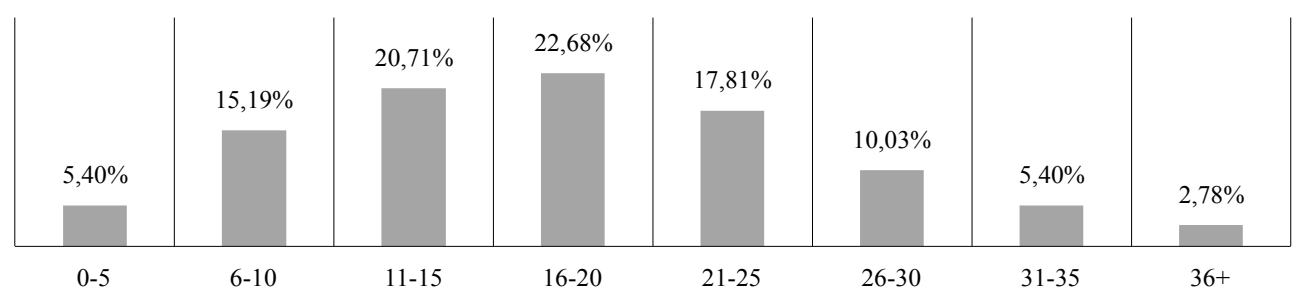

Cuadro 6. Extensión de los enunciados expositivos.

Sin embargo, hay alguna diferencia interesante: la primera tiene que ver con el mayor rendimiento de las dos franjas primeras, correspondientes a $1 / 10$ y que suman el $20,59 \%$ frente al 13,2\% consignado en los textos narrativos. Paralelamente, los enunciados de más de 30 palabras se reducen a algo más del $8 \%$, frente al 12\% de los narrativos. 
2.4. En los textos descriptivos solo se supera el $10 \%$ de frecuencia en cuatro franjas, que van de 6 a 25 palabras:

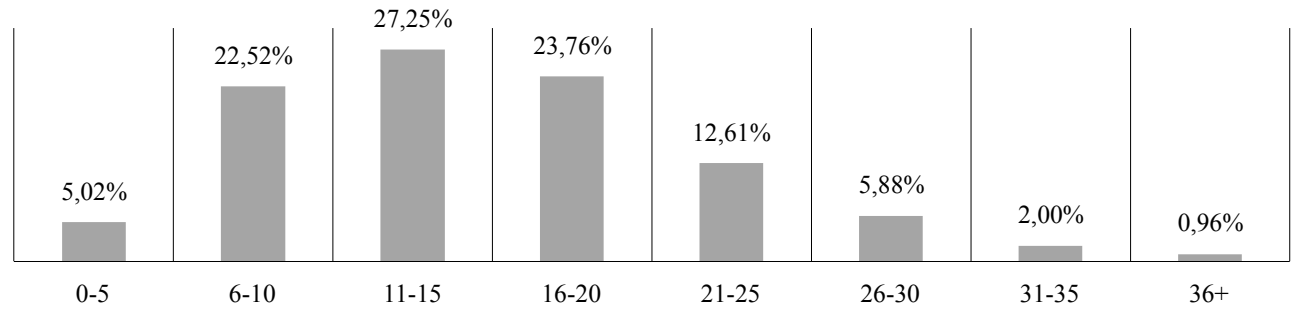

Cuadro 7. Extensión de los enunciados descriptivos.

Sin embargo, los resultados no resultan tan homogéneos como en el caso anterior. Por un lado, observamos que el segmento más usado se desplaza a 6-20: en las tres franjas incluidas se supera el $20 \%$ de frecuencia. Y dentro de dicho segmento hay, a su vez, cierta preferencia por la extensión entre 11 y 15 palabras, por encima del $27 \%$. Los enunciados con una longitud entre 21 y 25 palabras también superan el 10\%; sin embargo, su rendimiento no alcanza la mitad de las tres franjas antes indicadas.

El límite máximo en la construcción de enunciados parece estar en 26-30, de modo que los ejemplos por encima de esa extensión son residuales. Por lo que afecta a los enunciados menores, interesa destacar que en el texto descriptivo se considera más aceptable la inclusión de unidades más cortas, como lo demuestra el hecho de que las inferiores a 6 palabras suman casi un $28 \%$, mientras que en el caso de los textos narrativos estos suponían menos de la mitad: un $13 \%$.

2.5. Los enunciados en el texto de naturaleza instructiva son los más cortos: solo hay tres franjas, de 6 a 20, en las que se supera el 10\% de frecuencia:

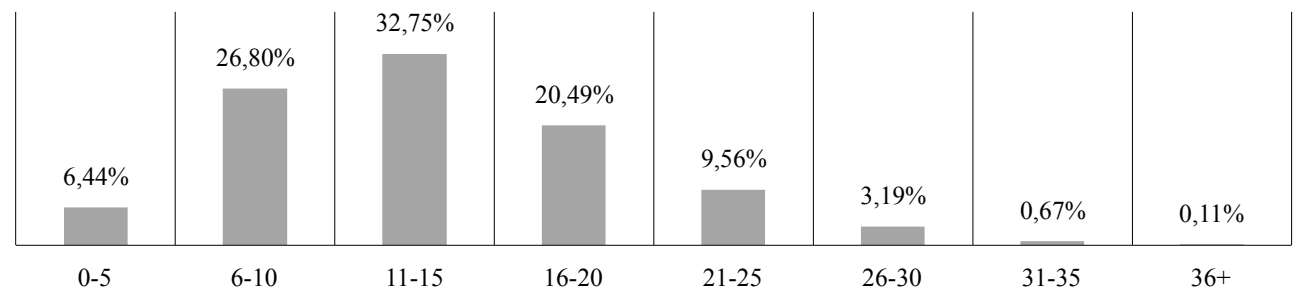

Cuadro 8. Extensión de los enunciados instructivos.

Se detecta una clara inclinación por la extensión entre 11 y 15 palabras, hasta el punto de que un tercio del total de los enunciados son de esa longitud: es el único caso de todo el estudio realizado en el que una franja supera el $30 \%$ de uso en cualquiera de los cuatro modos de discurso que hemos analizado. Del mismo modo destaca el rendimiento de la franja de 6 a 10 palabras: son algo más de una cuarta parte del total de los enunciados instructivos: de nuevo es la única ocasión en la que tal segmento supera la barrera del $25 \%$. En cambio, en la franja 21 a 25 no se alcanza (si bien por muy poco) el 10\%, lo que confirma la tendencia de los 
informantes a construir enunciados más cortos cuando se enfrentan a secuencias de naturaleza instructiva. Ello es coherente con la preferencia por evitar extensiones superiores a 25 palabras. 2.6. En conclusión, cabe afirmar que los enunciados narrativos y los expositivos tienden a ser los más extensos y variados, y se mueven en un rango entre 11 y 25 palabras; sin embargo, superar tal límite es más habitual en los primeros. Al mismo tiempo, los inferiores a 11 serán más frecuentes en el caso del discurso expositivo. Tales diferencias podrían tener que ver con las variaciones que se observan entre ambos tipos de texto en lo referido a complejidad sintáctica y densidad conceptual que analizaremos más adelante en este trabajo.

Por su parte, los enunciados descriptivos y los instructivos son los más cortos, y se mueven en un arco entre 6 y 20 palabras. Ahora bien, en el caso de los descriptivos, superar ese límite es razonablemente habitual, por lo que llega a afectar al 21,4\%; en cambio, el discurso instructivo apenas suma un 13,5\% en esa longitud de enunciado. En cualquier caso, en ambos casos se evita construirlos con una extensión superior a 30 palabras.

\section{NATURALEZA SINTÁCTICA DE LOS ENUNCIADOS}

Decíamos más arriba que el enunciado es una unidad del discurso que se formaliza en diferentes estructuras que gozan de independencia sintáctica y autonomía semántica. El estudio realizado nos ha permitido constatar que se plasma en tres unidades sintagmáticas y dos oracionales. Dentro de las primeras, cuya consideración será la misma que propone la Nueva Gramática de la Lengua Española (en adelante, $N G L E$ ), hemos identificado sintagmas nominales (SN) preposicionales (SPR) y adjetivos (SAJ); de manera conjunta los denominaremos grupos sintácticos no oracionales.

Por su parte, a la hora de analizar los enunciados de naturaleza oracional, en cuya categorización sintáctica suscribiremos en lo esencial la descripción establecida en la $N G L E$, nuestro punto de partida será la distinción establecida allí entre oraciones simples y compuestas:

Las oraciones simples establecen una relación predicativa, es decir, ponen en conexión un sujeto con un predicado siempre que no contengan otras oraciones que ocupen alguno de sus argumentos o modifiquen a alguno de sus componentes $(1.131)^{6}$.

Se denomina ORACIÓN COMPUESTA a la que contiene una o varias subordinadas. El concepto de oración compuesta se extiende también en la mayoría de los estudios a las oraciones formadas por coordinación de otras (1.13ñ).

Interpretaremos solo como compuestas aquellas que responden estrictamente a la primera parte de la definición académica, pues entendemos que la coordinación es un modo de relación sintáctica y no un tipo de unidad oracional.

Sobre la base de todo lo dicho, y considerando el número total de enunciados, el corpus arroja los resultados siguientes en los referido a los tres tipos de unidades formales subyacentes a los enunciados textuales; a saber, oraciones simples (OS), oraciones compuestas (OC) y grupos sintácticos no oracionales (GSNO):

6 Todas las referencias a epígrafes de la $N G L E$ se hacen respecto de la versión extendida de la misma. 


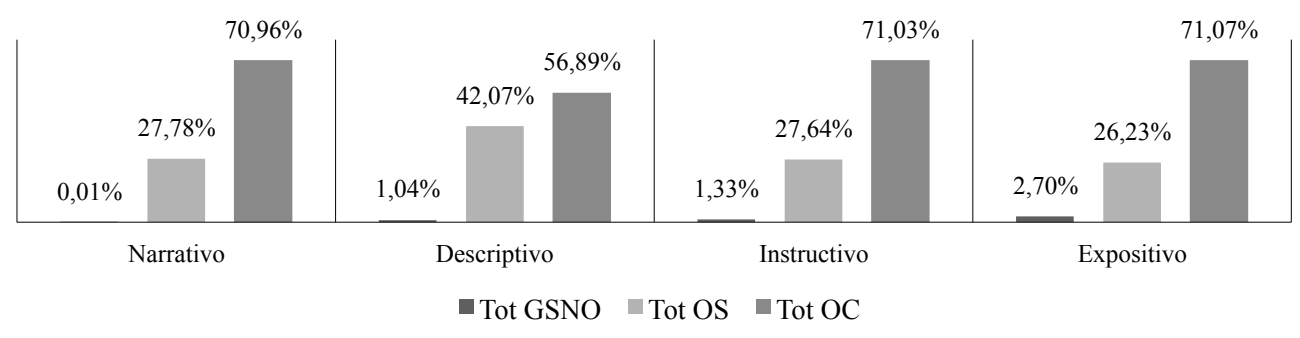

Cuadro 9. Rendimiento de las unidades sintácticas.

En los textos narrativos, instructivos y expositivos se observa que en aproximadamente el $70 \%$ de los casos el núcleo formal de los enunciados es una oración compuesta. En cambio, en los descriptivos esa frecuencia desciende al 56\%; al tiempo comprobamos que en estos últimos aumenta la construcción de enunciados que son sintácticamente oraciones simples hasta por encima del 40\%; sin embargo, los enunciados OS rondan el $27 \%$ en el caso de narrativos, instructivos y expositivos. Por su parte el uso de GSNO como soporte formal de enunciados textuales es testimonial. Tanto es así que solo en el caso de los expositivos superan el $2 \%$ de los ejemplos consignados.

\subsection{Grupos sintácticos no oracionales}

Los GSNO como base de la configuración de los enunciados textuales apenas dan cuenta de un $1,38 \%$ del total del corpus. Así, su uso solo ha de evaluarse desde una perspectiva cualitativa, en tanto que suponen una excepción a la tendencia normal, que no es otra que la construcción oracional como base sintáctica subyacente. De hecho, los datos nos permiten establecer una correlación casi exacta entre la unidad discursiva enunciado y la unidad formal oración. Veamos, en cualquier caso, cuál es el rendimiento de los diferentes GSNO:

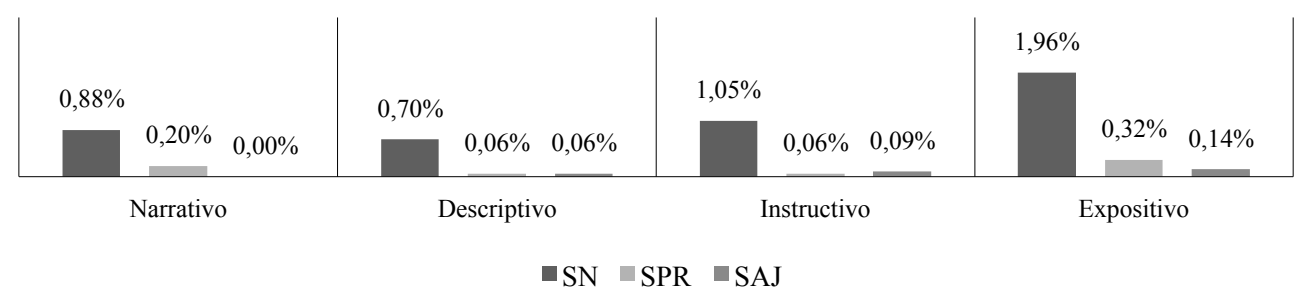

Cuadro 10. Uso de grupos sintácticos no oracionales (GSNO).

El análisis desagregado demuestra que solo los sintagmas nominales (SN) tienen algún rendimiento, puesto que son los únicos que superan el 1\% de uso. En cambio, se constata el escasísimo uso de los sintagmas adjetivos (SAJ), que son un $0,08 \%$ del total. Son SAJ las estructuras correspondientes a los enunciados que destacamos en cursiva:

2. Otra ventaja es el ahorro que los uniformes suponen para las familias. No sólo económico pero también de tiempo porque los estudiantes no tienen que pensar qué ponerse cada mañana. (E) 
3. Los expertos recomiendan música clásica. También puede servir cualquier otro tipo; pero, siempre a un volumen adecuado: lo bastante alto para que la criatura lo escuche y lo bastante bajo para que no le incomode (I).

Lo mismo sucede con los sintagmas preposicionales (SPR), que apenas alcanzan el 0,14\%. Podemos rescatar, no obstante, algún ejemplo:

4. Cuando finalmente la convencieron para que comiera, no quiso lentejas, filetes o fruta. Sólo le apetecía chocolate. $Y$ en grandes cantidades (E).

Desde un punto de vista formal, hemos de considerar aquellos casos en los que se insertan oraciones subordinadas en los GSNO. Distinguiremos, pues, grupos simples (GSNOS) y compuestos (GSNOC), que se distribuyen de la siguiente manera:

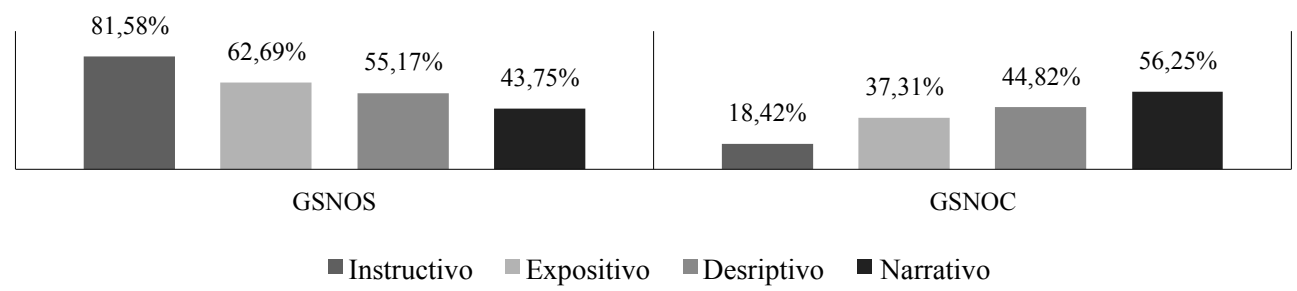

Cuadro 11. Grupos sintácticos no oracionales simples y compuestos.

La naturaleza de los enunciados incide directamente en la preferencia por unos u otros. Así, en los instructivos, y en menor medida en los expositivos, se tiende a limitar al máximo la complejidad sintáctica de los GSNO. En el extremo opuesto, observamos que en los narrativos se prefieren las versiones compuestas a las simples. Por otro lado, y desde un punto de vista cualitativo, es oportuno recordar que los GSNOC pueden llegar a acumular hasta cuatro predicaciones verbales subordinadas aun cuando lo más frecuente es que se trate de una o de dos:

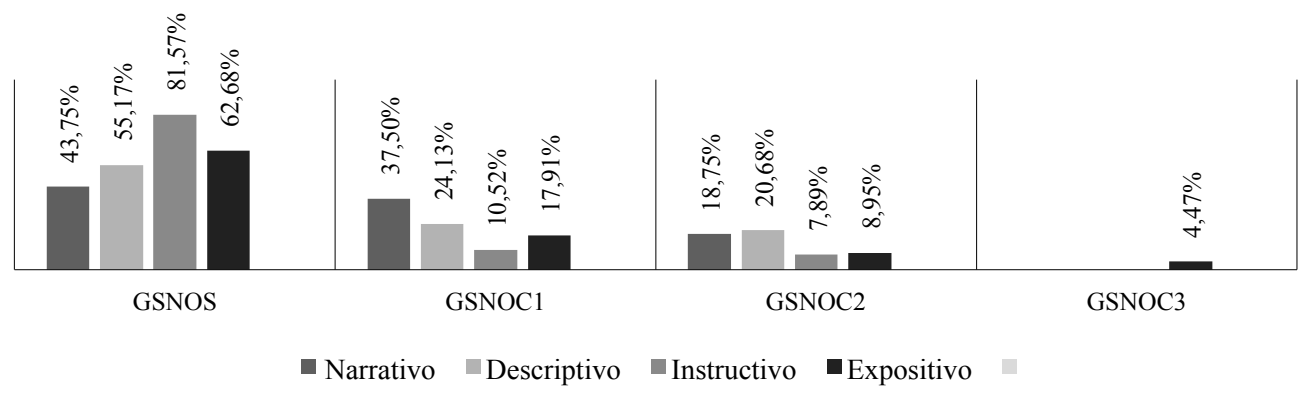

Cuadro 12. GSNOC: nivel de complejidad.

La mayor complejidad sintáctica, siempre dentro de lo limitado del uso, se ha detectado en el caso de los enunciados incluidos en textos expositivos. En el segundo enunciado del 
ejemplo siguiente se coordinan dos SN; el primero incluye una oración de relativo dentro de la que aparece una subordinada sustantiva de infinitivo y en el segundo hay otra de relativo en la que se inserta una construcción causal:

5. Da la impresión de que los padres, ante la terrible decisión de si vestir al hijo un pantalón verde o uno azul, no pueden ante la presión de los cuadros y las rayas, de lo que el crío quiere llevar y lo que está de moda. La madre que quiere comprar un chándal del Decathlon de esos de 12,50 y el chaval que quiere uno del Real Madrid, o del Barça, o del Mirandés, porque Fulanito de tal se ríe de él en el cole (E).

\subsection{Oraciones simples y compuestas}

3.2.1. Un $31 \%$ del total de los enunciados de nuestro corpus tienen como base formal una oración simple, si bien ese porcentaje no es en absoluto uniforme en los cuatro grupos textuales: suman en torno a un $27 \%$ en los enunciados narrativos, instructivos y expositivos frente al $42 \%$ en los descriptivos. En segundo lugar, observamos que, cuando los enunciados se construyen sobre la base de una OS, lo más frecuente es que esta no se coordine con otra u otras OS, como lo demuestra el hecho de que esa opción está siempre por encima del 75\% de frecuencia en todos los grupos.

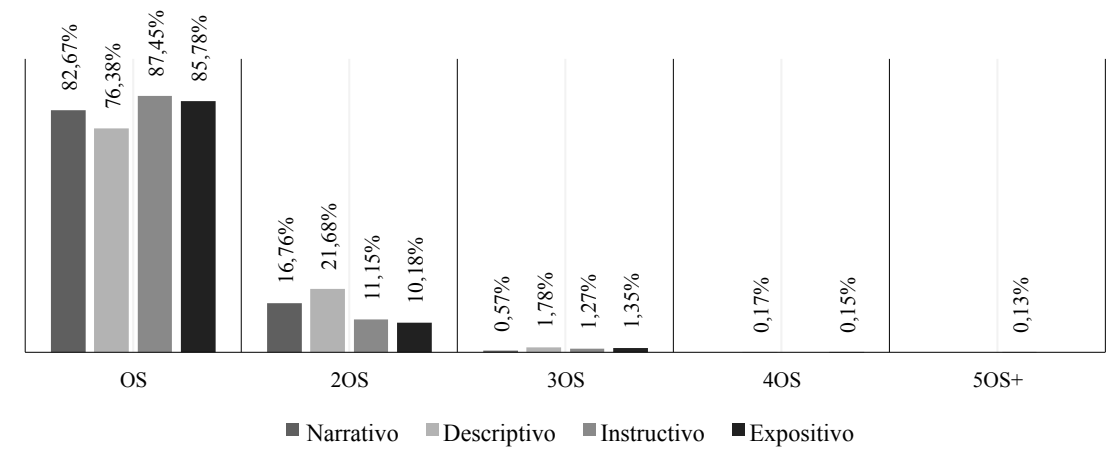

Cuadro 13. Enunciados con forma de oración simple.

Aun así, en los cuatro grupos de textos se han identificado enunciados donde se coordinan tres oraciones simples, y hay casos de coordinaciones por encima de cuatro en los instructivos, como sucede en la cuarta unidad del ejemplo siguiente:

6. Algunas formas de estimular al pequeñín son la música, los juguetes o la matronatación. Esta última sólo cuando es algo mayor. La televisión no es una buena forma de ayudarlo. Cántale a tu nene, léele, sonriele, háblale, míralo a los ojos, juega con él... (I).

3.2.2. Sin embargo, el $66,8 \%$ de los enunciados se construyen como oraciones compuestas. Tampoco ahora la distribución es uniforme. Esa tendencia alcanza el 71\% de las unidades en los textos narrativos, instructivos y expositivos; en cambio, en los descriptivos, desciende de hasta el $57 \%$ en beneficio de la construcción sobre base de oraciones simples. 
Si tomamos en consideración el número de predicaciones subordinadas que identificamos en cada OC, el análisis aporta los siguientes resultados:

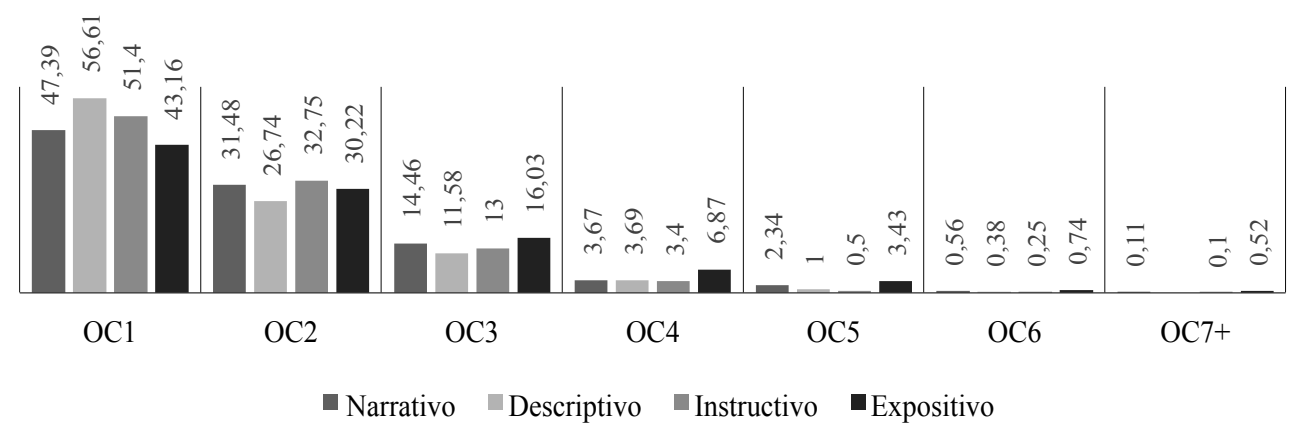

Cuadro 14. Predicaciones subordinadas por OC.

Los datos desvelan que nuestros informantes prefieren mayoritariamente construir enunciados sobre la base de oraciones compuestas que incluyan como máximo una o dos predicaciones subordinadas. Lo demuestra el hecho de que tal opción da cuenta del $79 \%$ de los casos en los textos narrativos, del $83 \%$ en los descriptivos, del $84 \%$ en los instructivos y del $73 \%$ en los expositivos. También tiene rendimiento la inclusión en el enunciado de tres verbos en subordinación (OC3): entre un 11 y un 16\%. Incluso la acumulación de cuatro alcanza cierta relevancia en el caso de los expositivos. Por contra, los enunciados con cinco o más apenas se utilizan. En todo caso, el número máximo de predicaciones subordinadas en un sola OC es de siete:

7. Si desea entretener o distraer a su hijo mientras está en la cuna, existen unos objetos llamados móviles formados por juguetes y formas colgantes que pueden sujetarse en ella (I).

Así y todo, según la naturaleza de los textos se pueden observar algunas pequeñas diferencias cualitativamente relevantes:

- En los textos descriptivos se prefieren decididamente los enunciados de una sola predicación, de modo que la variante OC1 reúne casi el 57\% de las OC identificadas.

- En los textos expositivos se produce una mayor dispersión, resultado de la cual hay una menor cantidad de enunciados $\mathrm{OC} 1$ en beneficio de los del tipo OC3 e incluso OC4: el deseo de aportar una mayor densidad informativa se traduce en un mayor grado de elaboración sintáctica

- Los textos narrativos e instructivos exhiben una distribución ciertamente parecida en lo que tiene que ver con el número de predicaciones verbales de naturaleza subordinada que se insertan en los enunciados construidos sobre la base de una OC. No obstante, los segundos muestran mayor tendencia a usar OC1. Sin embargo, prefieren evitar la construcción igual o superior a OC6.

En segundo lugar, podemos comprobar que los enunciados que se asientan sintácticamente en una OC se configuran de diversas formas: 


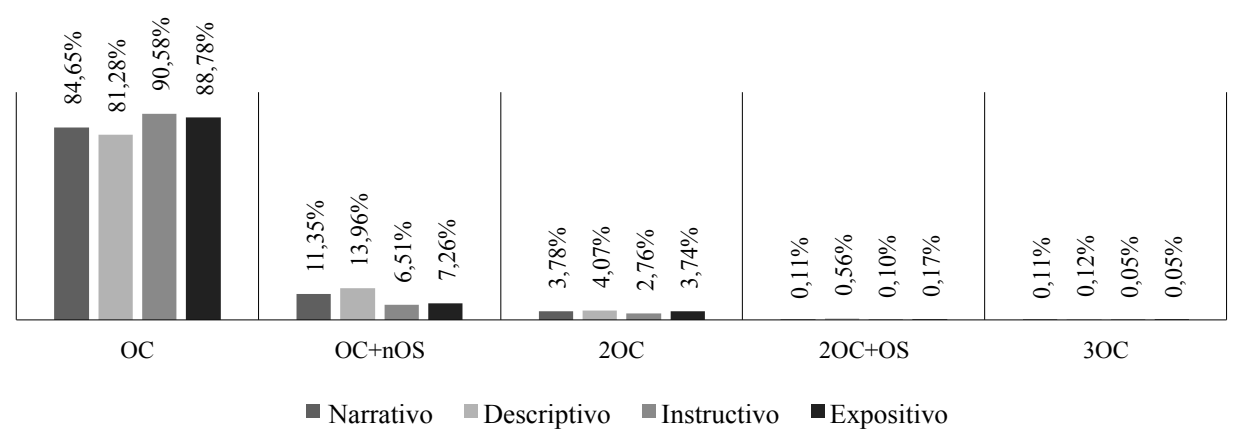

Cuadro 15. Naturaleza sintáctica de las OC.

Como vemos, lo más frecuente es que formalmente se construyan sobre la base de una sola oración compuesta. Así sucede en un rango entre el 81\% (descripción) y el 90\% (instrucción). La alternativa más usada es que se coordinen una OC y una (o más) OS. La suma de ambas opciones alcanza entre el $95 \%$ y el $97 \%$ en los cuatro grupos analizados. Esto tiene como resultado que las opciones restantes sean residuales: a saber, la coordinación de dos o más OC o de dos OC y una OS. Además, se observa que, cuando se prolonga el enunciado por la vía de la coordinación oracional, se prefiere vincular una OC con una o varias OS a hacerlo con una o más OC.

\subsection{Comparativa de grupos sintácticos}

El trabajo llevado a cabo nos ha permitido identificar quince patrones sintácticos diferentes que hemos ordenado atendiendo a su frecuencia total en el corpus:

\begin{tabular}{|l|r|r|r|r|r|}
\cline { 2 - 6 } \multicolumn{1}{c|}{} & Narrativo & Descriptivo & Instructivo & Expositivo & Total \\
\hline OC & $60,06 \%$ & $46,24 \%$ & $64,34 \%$ & $63,09 \%$ & $58,04 \%$ \\
OS & $22,97 \%$ & $32,13 \%$ & $24,17 \%$ & $23,09 \%$ & $26,10 \%$ \\
OC+nOS & $8,05 \%$ & $7,94 \%$ & $4,62 \%$ & $5,16 \%$ & $6,22 \%$ \\
OS & $4,66 \%$ & $9,12 \%$ & $3,08 \%$ & $2,74 \%$ & $5,00 \%$ \\
GOC & $2,68 \%$ & $2,32 \%$ & $1,96 \%$ & $2,66 \%$ & $2,35 \%$ \\
GSNOS & $0,55 \%$ & $0,57 \%$ & $1,09 \%$ & $1,69 \%$ & $1,02 \%$ \\
3OS & $0,16 \%$ & $0,75 \%$ & $0,35 \%$ & $0,36 \%$ & $0,45 \%$ \\
GSNOC1 & $0,47 \%$ & $0,25 \%$ & $0,14 \%$ & $0,48 \%$ & $0,31 \%$ \\
GSNOC2 & $0,24 \%$ & $0,21 \%$ & $0,11 \%$ & $0,24 \%$ & $0,19 \%$ \\
2OC+OS & $0,08 \%$ & $0,32 \%$ & $0,07 \%$ & $0,12 \%$ & $0,16 \%$ \\
3OC & $0,08 \%$ & $0,07 \%$ & $0,04 \%$ & $0,04 \%$ & $0,05 \%$ \\
GSNOC4 & $0,00 \%$ & $0,00 \%$ & $0,00 \%$ & $0,16 \%$ & $0,04 \%$ \\
GSNOC3 & $0,00 \%$ & $0,00 \%$ & $0,00 \%$ & $0,12 \%$ & $0,03 \%$ \\
4OS & $0,00 \%$ & $0,07 \%$ & $0,00 \%$ & $0,04 \%$ & $0,03 \%$ \\
5OS+ & $0,00 \%$ & $0,00 \%$ & $0,04 \%$ & $0,00 \%$ & $0,01 \%$ \\
\hline
\end{tabular}

Cuadro 16. Comparativa de grupos sintácticos. 
De ellos, hay 5 modelos de construcción sintáctica que acumulan el 97\% de las unidades evaluadas. Las dos más habituales son configuraciones no coordinadas (OS y OC). Las tres siguientes coordinan respectivamente una OC y una o más OS, dos OS y dos OC.

Nueve de las opciones exhiben un uso inferior al $1 \%$ y cinco están por debajo del $0,1 \%$, lo que las convierte en residuales en términos cuantitativos, pero muy interesantes desde un punto de vista cualitativo, por lo que serían acreedoras de un estudio específico que, desgraciadamente, excede con mucho los límites y objetivos de esta investigación. No obstante, es llamativo que, de ellas, cuatro se detectan en los textos expositivos. Estos se convierten, pues, en los sintácticamente más diversos.

\subsection{Naturaleza sintáctica y tipología textual}

A la hora de valorar la importancia de cada configuración sintáctica desde la naturaleza tipológica de los textos evaluados, limitaremos el análisis a aquellas construcciones que muestran una frecuencia de uso superior al 1\%. En primer lugar, observamos cómo los textos instructivos y los expositivos exhiben un uso muy similar de las opciones. Seis combinaciones se sitúan en ambos casos por encima del 1\% de frecuencia y la prelación es idéntica en los dos grupos de texto:

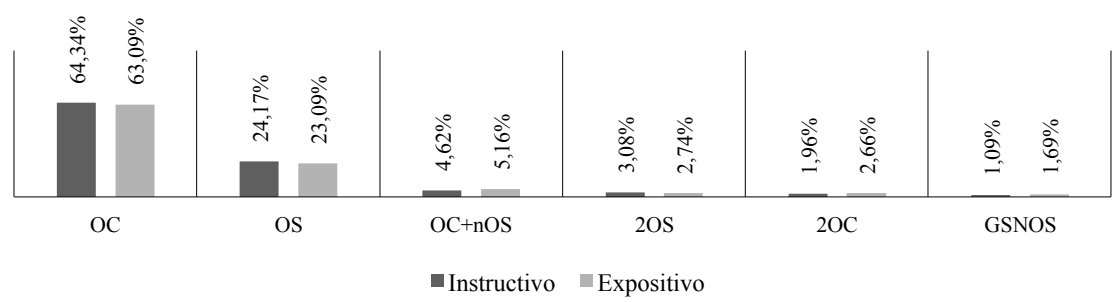

Cuadro 17. Enunciados instructivos y expositivos: configuración sintáctica.

Los porcentajes son casi idénticos en las tres opciones más frecuentes y suman el 93,1\% en los instructivos y el $91,2 \%$ en los expositivos. Las oraciones compuestas (OC) reúnen algo menos de dos terceras partes de los casos mientras que las simples (OS) acumulan casi una cuarta parte. En torno al 5\% de los enunciados muestran la combinación de una oración compuesta y una o más oraciones simples.

Por su parte, los narrativos muestran una preferencia algo menor por las $\mathrm{OC}$, mientras que la combinación OC+NOS dobla la frecuencia observada en expositivos e instructivos, y lo mismo sucede con $2 \mathrm{OC}$ y $2 \mathrm{OS}$. En cambio, ninguna de las opciones de enunciados asentados sobre la base de grupos sintácticos no oracionales supera el $1 \%$ de presencia en el corpus:

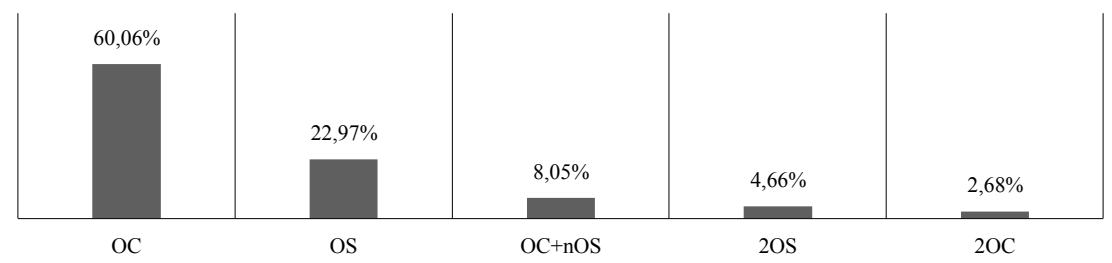

Cuadro 18. Enunciados narrativos: configuración sintáctica. 
En los textos narrativos se ha usado un número menor de patrones sintácticos, pero los que se utilizan y son diferentes de OC y OS tienen más rendimiento que en el caso de los expositivos y los instructivos. Por ello, las opciones coordinadas de dos compuestas, dos simples o una compuesta más una o más simples reúnen el 15\% de los enunciados analizados, un porcentaje sensiblemente superior al que se constata en el caso de los instructivos $(9,66 \%)$ y los expositivos $(10,56 \%)$.

Las mayores diferencias se observan en la construcción de enunciados en el marco de textos descriptivos:

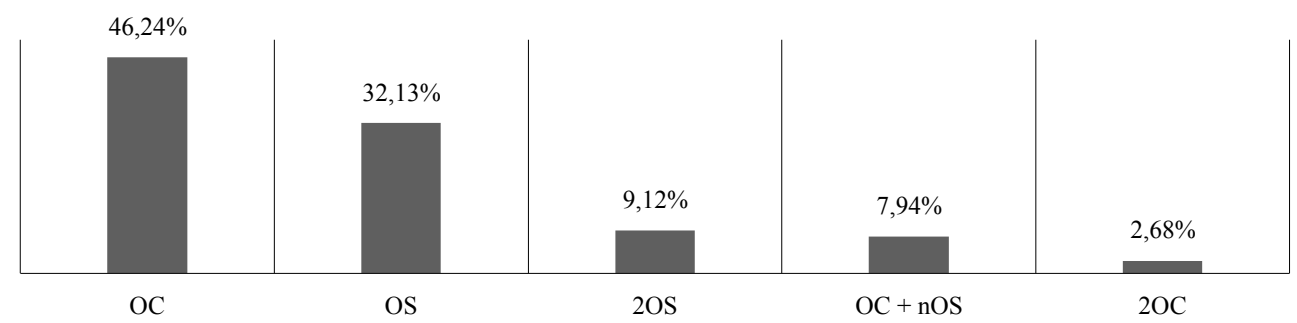

Cuadro 19. Enunciados descriptivos: configuración sintáctica.

En primer lugar, vemos que los enunciados OC alcanzan el 46\%; es decir, entre quince y veinte puntos menos que en las opciones restantes. En cambio, los enunciados OS superan el 32\%; esto es, en torno a diez puntos más que en narrativos, expositivos e instructivos. Por otro lado, hay un cambio cualitativo importante frente a los otros tres modos discursivos: el tercer patrón más utilizado ya no es OC+NOS, sino la coordinación de dos oraciones simples: se alcanza un $9 \%$, mientras que en los otros tres modos del discurso se movía entre el $2 \%$ y el $4,5 \%$. Así pues, el aprovechamiento de la OS, ya sea de manera aislada o coordinada con otra de su misma naturaleza, alcanza el $41 \%$ de los casos, muy por encima del $27,63 \%$ del narrativos, el $25,83 \%$ de los expositivos y el $27,25 \%$ de los instructivos. Todo ello nos permite afirmar que el enunciado descriptivo es sintácticamente el más sencillo.

\subsection{Incrustación oracional}

Se denomina incrustación sintáctica ${ }^{7}$ al proceso de inserción de una unidad dentro de otra de similar naturaleza. La incrustación oracional se evaluaría, por tanto, desde la perspectiva del estudio de la subordinación. Los trabajos realizados en esta línea investigadora se han centrado habitualmente en la ubicación de la incrustación en relación con los márgenes de la oración. Sin embargo, también ha sido asociada al nivel de inteligibilidad textual en aquellos trabajos que tienen como objeto de estudio la comprensión lectora. Así, cabe citar entre ellos el de Anula (2007: 53), para quien "los textos con muchas oraciones incrustadas o con estructuras recursivas incrementan notablemente la complejidad de los textos y provocan efectos negativos en la comprensión lectora". Asimismo, se la ha vinculado al concepto de densidad textual; tal es el caso de Gallardo Paúls (2008), quien mide la

7 Traducimos de esta forma el término syntactic embedding, habitualmente utilizado en los estudios lingüísticos en lengua inglesa dedicados a esta cuestión. 
complejidad sintáctica de los textos a partir de los siguientes parámetros: longitud media de oración y proposición, tipo de subordinación y grado de incrustación subordinada. Así pues, un nivel de incrustación oracional elevado es propio de textos conceptualmente complejos e informativamente menos lineales, lo que obliga a construir relaciones y jerarquías más sofisticadas; por otro lado, y como consecuencia de lo anterior, serán textos cuya comprensión exigirá un grado mayor de esfuerzo al tener un nivel de accesibilidad más bajo.

En lo que atañe a nuestra investigación, entenderemos que el nivel de incrustación más sencillo supone la inserción de una subordinada dentro de una OP (I1). A partir de ahí, la incrustación se puede complicar formalmente en virtud del número de capas que la conformarían. El máximo de incrustaciones que hemos descubierto en el corpus asciende a seis, que se observan en el segundo enunciado del ejemplo siguiente:

8. Ya se ha emitido un comunicado oficial con el balance de pérdidas que ha causado este tifón, donde destaca el impactante de número de fallecidos, que se encuentra alrededor de 300000 personas. Se estima que los daños materiales ascienden a cientos de millones de dólares, por lo que el gobierno ha solicitado la ayuda internacional para el abastecimiento de los materiales necesarios para la reconstrucción de infraestructuras, así como de bienes de primera necesidad, ya que un día después del desastre, numerosos supermercados y gasolineras se han quedado sin suministros, vendidos a personas que todavía luchan por sobrevivir, pero con un futuro menos halagüeño que la semana pasada $(\mathrm{N})$.

No obstante, en el 95\% de las unidades evaluadas el grado de incrustación oscila entre cero y dos:

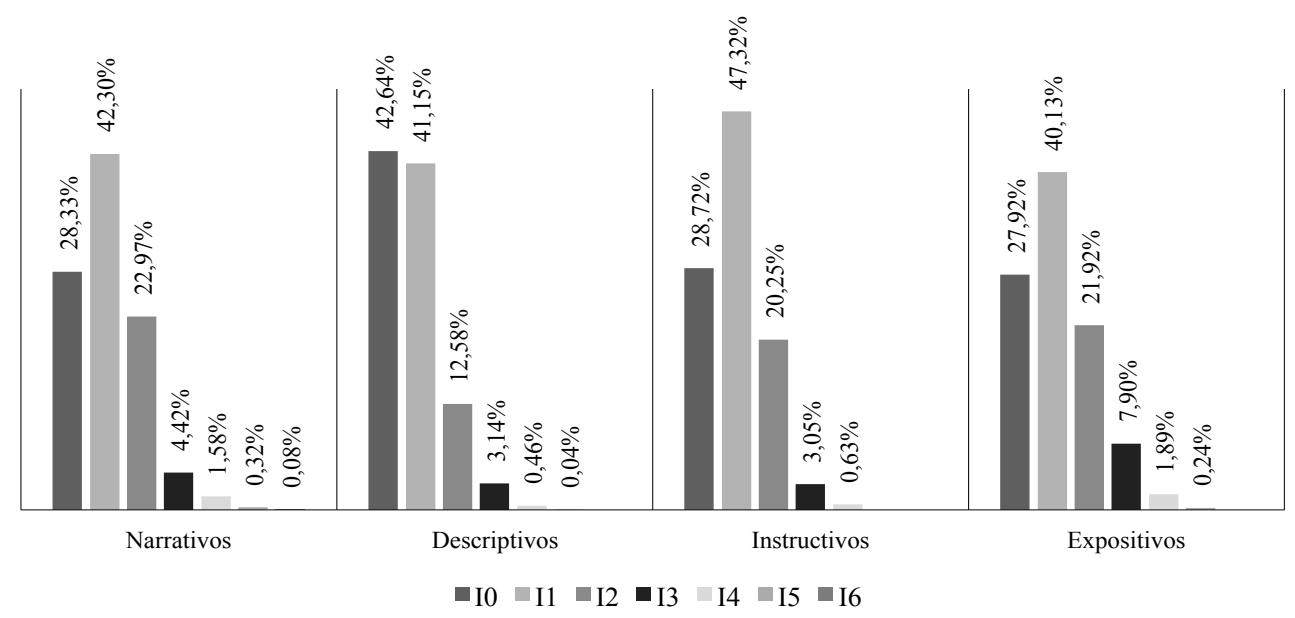

Cuadro 20. Incrustación oracional.

Desde el punto de vista de la naturaleza secuencial de los textos, las diferencias más notables vuelven a estar en el texto descriptivo, en el que el nivel cero de incrustación (I0) es la opción más frecuente. Y, lo que es más importante, se trata del único modo discursivo en el que su frecuencia es superior a la del grado uno (I1). En segundo lugar, y porque tiene que ver con el número de incrustaciones, cabe destacar varios hechos. El primero nos revela que I1 es 
el modelo de mayor frecuencia global. Es, sin embargo, llamativo que en los expositivos tiene un rendimiento algo menor que en el resto de contextos discursivos. La explicación es sencilla: el enunciado expositivo tiene los niveles de incrustación más complejos; así, I4 casi alcanza el $2 \%$ y, lo que es aún más llamativo, I3 se acerca al $8 \%$, casi el doble del promedio de esa banda en el total del corpus. Y por lo mismo, su porcentaje de I0 es el más bajo en todo el corpus.

\subsection{Rendimiento de la coordinación}

La siguiente cuestión en la que nos queremos centrar es en la incidencia de la coordinación en la construcción de los enunciados. Decíamos antes que la entendemos no como un tipo de oración sino de relación que se puede establecer en el marco de distintas categorías sintácticas. En nuestro trabajo recogeremos exclusivamente las coordinaciones homocategoriales de predicaciones dentro de la unidad oracional en la que se insertan. Así, consideraremos la coordinación entre oraciones simples, entre oraciones compuestas, entre oraciones simples y compuestas, entre verbos auxiliados en las perífrasis, entre oraciones subordinadas independientes y entre predicaciones dentro de oraciones subordinadas.

El estudio nos ha permitido identificar ejemplos correspondientes a tres tipos de coordinaciones según la naturaleza de la relación establecida: copulativas, adversativas y disyuntivas. A su vez, del total de relaciones coordinativas, un $9,68 \%$ se construye de manera yuxtapuesta; esto es, sin uso explícito de un nexo que nos permita clasificar en alguno de los tres grupos antes citados. Por ello, se ha hecho necesario analizar e interpretar cada una de esas relaciones yuxtapuestas con el fin de poder adscribirlas a uno u otro grupo. Una vez reajustados los valores relativos de cada grupo, los resultados son los siguientes:

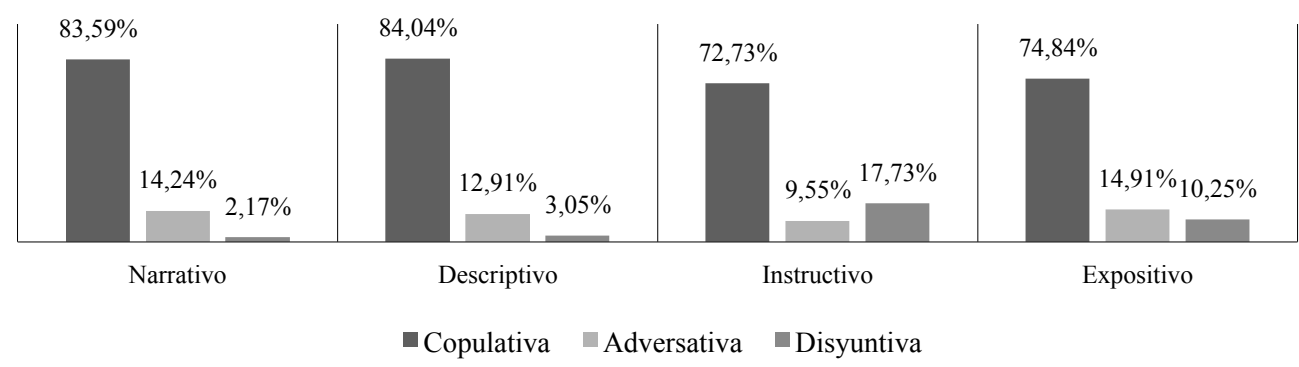

Cuadro 21. Rendimiento de la coordinación.

En el cómputo total se observa una preferencia evidente por la coordinación de naturaleza copulativa, que reúne cerca del $80 \%$ de las detectadas en el corpus. La segunda opción es la relación adversativa; no obstante, la frecuencia de uso no es mucho mayor que en el caso de las disyuntivas: un $12 \%$ frente a un $8 \%$.

Sin embargo, el análisis desagregado desde la tipología textual nos revela datos ciertamente interesantes. En primer lugar, observamos que la coordinación disyuntiva es testimonial en los textos narrativos y descriptivos, donde tiene un rendimiento en el corpus inferior o igual al 3\%. Tal hecho tiene como resultado que suba la proporción de la copulativa pero no tanto la adversativa. En segundo lugar, destaca que en los textos instructivos el uso de la disyuntiva supera la adversativa; es el único grupo en que se observa tal inversión. Por 
último, comprobamos que la frecuencia de las copulativas en expositivos e instructivos desciende en torno a un $10 \%$ en comparación con narrativos y descriptivos; como resultado de ello, la suma de las dos coordinaciones alternativas supera por poco el $25 \%$; sin embargo, las preferencias no son las mismas: en los instructivos se opta antes por las disyuntivas mientras que en las exposiciones se prefieren las adversativas. La explicación parece estar en que en el discurso expositivo la relación adversativa tiene más rendimiento en contextos donde se identifique con claridad su dimensión argumentativa:

9. Por todo eso, es verdad que llevar una vida sana y activa es positivo tanto para el cuerpo como para la mente, pero la felicidad también está en esos pequeños placeres que supone el tomar un chocolate o una hamburguesa de vez en cuando, sin obsesionarse por ello (E).

En cambio, en el texto instructivo, la preferencia por la coordinación disyuntiva tendría que ver con la propuesta de sugerencias alternativas para llevar a cabo una misma tarea:

10. Si no está segura de estar embarazada, vaya al médico o compre un test en la farmacia (I).

\section{CONFIGURACIÓN DE LAS PREDICACIONES EN LOS ENUNCIADOS}

Estudiar la configuración de las predicaciones de los enunciados nos va a aportar información relativa a su complejidad conceptual, desde la asunción de que esta es directamente proporcional al número de ellas que se combinan en tanto que estas funcionan como núcleos clausales. En ello seguimos en lo esencial a Berko y Bernstein (1999/2001: 256 y ss.): en cada unidad enunciado procesamos el lenguaje mediante cláusulas, que podrán ser principales o subordinadas: recogemos y analizamos la estructura y el significado de una cláusula, y almacenamos provisionalmente ese análisis en la memoria; a continuación, hacemos el mismo proceso con el resto de cláusulas identificables en cada unidad; finalmente se lleva a cabo una tarea de integración en la que combinamos la información de unas cláusulas con otras. Por tanto, cuantas más compongan el enunciado, más tiempo de procesamiento será necesario para llevar a cabo el proceso de comprensión, pues la estructura conceptual final será más compleja.

Así pues, desde un punto de vista cuantitativo, interesa examinar cuántas predicaciones se combinan por enunciado, puesto que de tal análisis podremos extraer conclusiones vinculadas a su grado de densidad conceptual. Y desde una perspectiva cualitativa habrá que detenerse en la naturaleza morfológica de los predicados. En ese sentido, parece oportuno fijarse en dos cuestiones: la primera de ellas persigue valorar el rendimiento de las formas no personales del verbo y la segunda se centra en el uso de las perífrasis verbales.

\subsection{Análisis cuantitativo}

En términos generales podemos afirmar que la configuración de predicaciones por enunciado en nuestro corpus es razonablemente uniforme con independencia de la naturaleza discursiva de los textos. Observamos que el promedio es muy estable, entre 2,19 y 2,58, y lo mismo sucede con la moda, que es en todos los casos de 2; solo hay alguna diferencia apreciable en el número máximo de predicaciones por tipo textual analizado: 


\begin{tabular}{|lrrrrrr|}
\multicolumn{1}{l}{} & Promedio & Moda & Máximo & Mínimo & Predicaciones & Enunciados \\
\hline Narrativos & 2,52 & 2 & 11 & 0 & 3.199 & 1.267 \\
Descriptivos & 2,19 & 2 & 8 & 0 & 6.152 & 2.807 \\
Instructivos & 2,36 & 2 & 9 & 0 & 6.766 & 2.855 \\
Expositivos & 2,58 & 2 & 12 & 0 & 6.408 & 2.482 \\
& & & & & & \\
Total & 2,41 & 2 & 10 & 0 & 22.525 & 9.411 \\
\hline
\end{tabular}

Cuadro 22. Predicaciones por enunciado.

Si desagregamos los datos considerando el número de predicaciones y el tipo textual, podemos interpretar resultados mucho más precisos y ciertamente interesantes. Los enunciados descriptivos serían los menos densos:

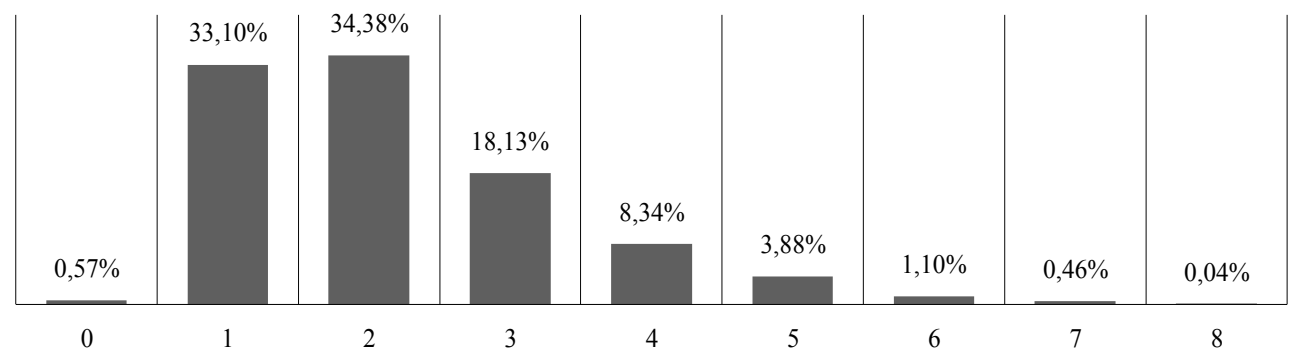

Cuadro 23. Predicaciones en enunciados descriptivos.

Observamos que algo más de dos tercios del total se distribuyen de forma casi idéntica entre unidades de 1 o 2 predicaciones; como resultado de ello, es el único modo del discurso en el que no se alcanzan en los de 3 el 20\% ni el 10\% en los de 4 . Finalmente, los enunciados de 5 o más predicaciones apenas acumulan el algo más del $5 \%$.

Por su parte, los enunciados narrativos e instructivos muestran similitudes en tanto que ofrecen un modelo de construcción muy parecido:

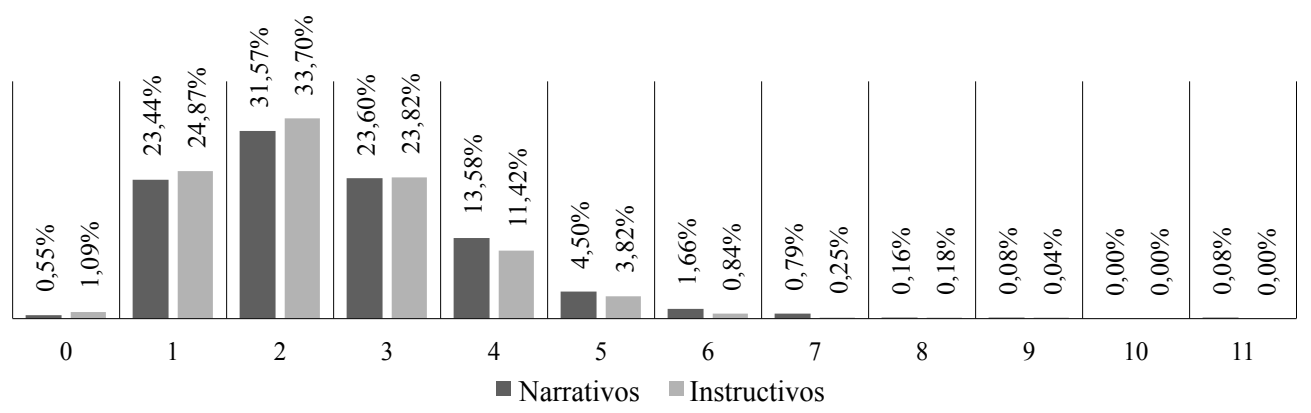

Cuadro 24. Predicaciones en enunciados narrativos e instructivos. 
Casi un tercio de ellos son de 2 predicaciones (algo menos en las narrativas); casi un $25 \%$ son de 1; otro tanto, de 3; y aproximadamente un $12 \%$, de 4 . En los enunciados de 1, 2 o 3 predicaciones, el porcentaje de frecuencia es siempre ligeramente superior en el caso de los textos instructivos, lo que significa que en estos las unidades tienden a ser algo menos densas. Se comprueba tal hecho en que las unidades de cuatro o más suman casi el $21 \%$ en los narrativos frente al $16 \%$ en los instructivos. Así pues, las diferencias solo se detectan en los enunciados más complejos.

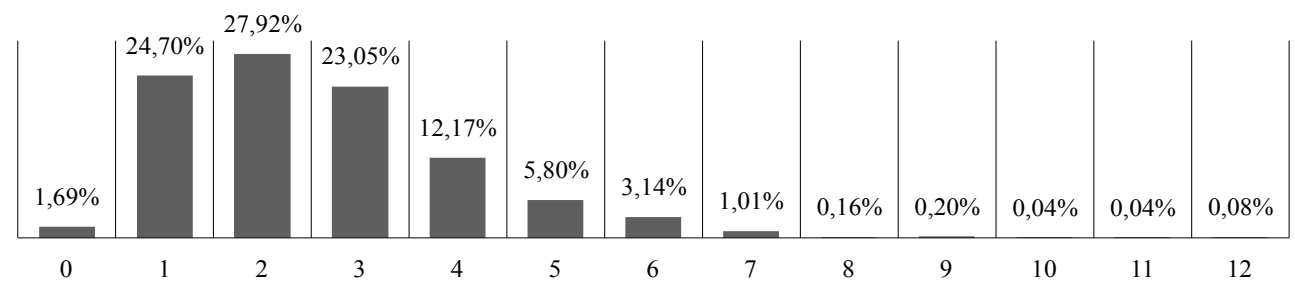

Cuadro 25. Predicaciones en enunciados expositivos.

En los textos expositivos descubrimos el menor número de enunciados de 2 predicaciones: es el único grupo en el que el porcentaje está por debajo del 30\%. Las unidades de 1, 3 y 4 predicaciones se comportan, sin embargo, como en los grupos narrativo e instructivo. La diferencia fundamental está en las unidades con un número igual o superior a 5: mientras que en los otros grupos supone el 5\% (instructivos y descriptivos) o el 7\% (narrativos), en los expositivos dobla ese porcentaje y llega casi al 11\%. De hecho, es en los textos expositivos donde los enunciados de 6 y 7 predicaciones verbales exhiben un rendimiento superior al $1 \%$, que eran residuales en el resto de las opciones textuales. Todo ello nos permite concluir que son las unidades más densas.

\subsection{Naturaleza morfológica de las predicaciones verbales}

Por lo que toca a la configuración morfológica de las predicaciones estableceremos el análisis sobre la base de tres opciones: formas conjugadas, formas no personales y perífrasis verbales:

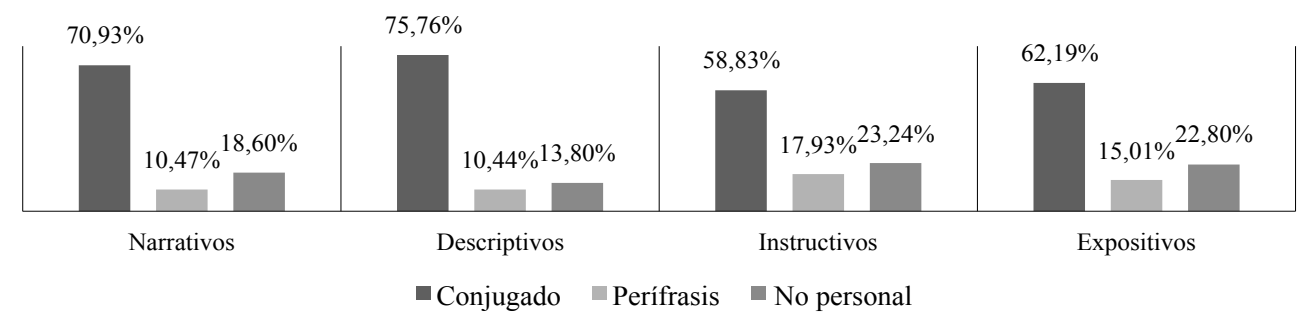

Cuadro 26. Morfología de las predicaciones verbales.

4.2.1. Como era de esperar, las formas conjugadas son las más habituales, con un promedio por encima del 66\%; en segundo lugar, las formas no personales de los verbos rozan el 20\%; 
por último, las perífrasis exhiben un uso medio de casi el 14\%. Este orden en la preferencia se repite en los cuatro modos del discurso; sin embargo, se observan diferencias en lo que tiene que ver con el grado de aprovechamiento de las tres variantes en cada uno de ellos.

En el texto descriptivo nuestros informantes prefieren sin ninguna duda las formas conjugadas, hasta el punto de que es el único tipo textual en el que su uso supera el $75 \%$ de las elecciones: 10 puntos por encima de la media. En cambio, exhiben el uso más restringido de las construcciones perifrásticas, que descienden al 10\% cuando el promedio está casi en el 14\%. Del mismo modo, las formas no personales cumplen en ellos una función limitada en torno al 13\%.

Los enunciados en texto narrativo son los segundos más proclives a usar formas conjugadas, pero casi cinco puntos porcentuales por debajo que en los descriptivos. Su uso de las formas no personales roza el promedio total, mientras que el de las perífrasis es sensiblemente inferior.

Por su parte, observamos que las variantes morfológicas en los enunciados correspondientes a textos expositivos se comportan de la manera más estandarizada, por lo que exhiben el uso más cercano a los promedios totales. Tal hecho se comprueba muy especialmente en el aprovechamiento de las formas no personales y de las perífrasis.

En cambio, las unidades más marcadas desde el punto de vista que ahora nos ocupa son indudablemente las de textos instructivos: es en ellos donde menos rendimiento tienen las formas conjugadas, que no llegan al 60\%: casi 20 puntos menos que en los descriptivos y 10 que en los narrativos; al mismo tiempo las perífrasis y las construcciones no personales muestran los porcentajes de frecuencia más elevados de todo el corpus: entre tres y cuatro puntos por encima de la media en ambos casos.

4.2.2. El análisis relativo a las formas no personales no ofrece otras dificultades que no sean las de distinguir si, cuando nos enfrentamos a infinitivos y participios, se trata de auténticas formas verbales o si estas han sufrido ya procesos completos de nominalización o adjetivación respectivamente. Para establecer las distinciones pertinentes asumiremos la descripción defendida en al NGLE. En el caso de los primeros, esta sostiene que la admisión de formas plurales, del uso del artículo y de adjetivos son índices de nominalización. Por lo que afecta a los participios, la gramática académica arguye que, frente a los adjetivos, pueden ir acompañados de complementos predicativos, admiten adverbios de modo y no permiten la anteposición al sustantivo sobre el que inciden, salvo en las llamadas construcciones absolutas.

Las formas no personales se utilizan en construcciones que tradicionalmente se han denominado de infinitivo, gerundio o participio. Su rendimiento se resume en el cuadro siguiente:

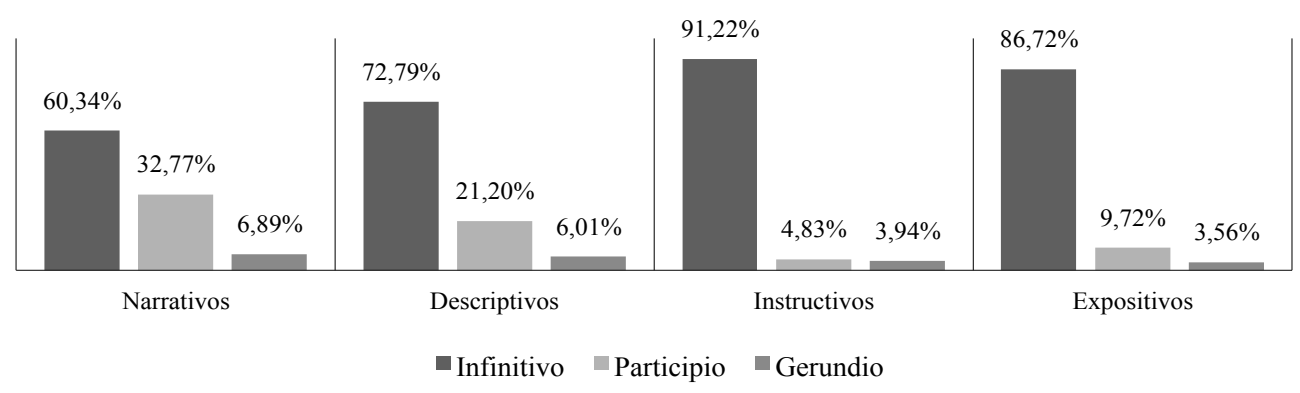

Cuadro 27. Uso de las formas no personales del verbo. 
Es evidente que las construcciones de infinitivo son las más frecuentes y que las menos utilizadas son las de gerundio. Así se observa en los promedios totales del corpus, donde las primeras superan el $80 \%$ de las predicaciones construidas con formas no personales del verbo, mientras que las segundas no alcanzan el 5\%. Algo más frecuentes son las de participio, en torno al $13 \%$.

No obstante, una vez más se observan diferencias interesantes según los tipos de texto considerados en el análisis. De hecho, se puede afirmar que el corpus de distribuye en tres grandes grupos. En el primero estarían los textos instructivos, en los que, como veíamos antes, el uso de las formas no personales es el más frecuente, por encima del $23 \%$; pero se limita casi exclusivamente al infinitivo, que reúne más del $90 \%$ de los casos, mientras que las construcciones de gerundio y las de participio son residuales. En segundo lugar, están los enunciados correspondientes a textos de naturaleza expositiva, que eran los que exhibían un uso de las formas no personales más ajustado al promedio. Pues bien, la distribución entre las tres alternativas vuelve a ser la más cercana a la representada por los valores totales. Finalmente, están los enunciados correspondientes a textos narrativos y descriptivos. En ambos casos se observa una mayor propensión a utilizar las construcciones de participio: en los narrativos suponen una tercera parte de las formas no personales y en los descriptivos, una quinta parte. Teniendo en cuenta que los participios se utilizan casi exclusivamente en las construcciones adjetivas y, aunque en menor medida, en las atributivas y semicopulativas, hay que entender que estas construcciones sintácticas van a ser distintivas de estos modos del discurso. Así lo demuestran los datos del análisis: las adjetivas suponen el 6,13\% de las predicaciones subordinadas en los textos narrativos y el $8,13 \%$ en el caso de los descriptivos. En cambio, suman el 1,65\% en los expositivos y apenas el 0,11\% en los instructivos. En cuanto a las atributivas, explican la diferencia de frecuencia entre narrativos y descriptivos: en las primeras suman el 5,45\%, mientras que en las segundas se reducen al $2,75 \%$.

4.2.3. Sin duda, resulta mucho más espinosa la cuestión de las perífrasis verbales porque no hay consenso a la hora de establecer los rasgos que las definen ni, consecuentemente, en el momento de fijar la nómina de unidades. La NGLE se detiene de manera muy exhaustiva en sus características funcionales. A la hora de distinguir construcciones perifrásticas, semiperifrásticas y no perifrásticas, establece cinco criterios para identificar los verbos auxiliares que generan las primeras: aceptan la proclisis del pronombre átono, rechazan la pasiva (aunque esta se puede construir sobre el auxiliado), no restringen semánticamente los sujetos pero concuerdan con ellos, no seleccionan los complementos del nombre y no seleccionan el verbo auxiliado.

El problema residiría en que muchas unidades satisfacen todos los criterios, pero otras solo algunos; por ello, buena parte de la investigación sobre perífrasis se ha detenido en establecer cuáles son los parámetros que debemos aplicar a la hora de identificarlas. En este sentido es muy interesante la propuesta de Fernández Martín (2014), quien crea a partir del modelo del prototipo un sistema para evaluar cuánto se acercan en términos cuantitativos a él las diferentes unidades analizadas; aplica once pruebas en tres niveles de lengua (morfología, sintaxis y semántica) y asigna a cada una de ellas un valor porcentual hasta un total de 10 puntos.

Efectivamente, los distintos trabajos referidos a perífrasis coinciden en asignar la capacidad de generarlas a determinados verbos: serían construcciones inequívocamente peri- 
frásticas. Sin embargo, se observa poco consenso a la hora de decidir sobre otras muchas. Por todo ello, hemos decidido seleccionar ocho criterios y evaluar cómo se comportan en relación con ellos las combinaciones de verbo conjugado e infinitivo identificadas en nuestro corpus y susceptibles de ser consideradas perífrasis. Son estos:

- El verbo auxiliado selecciona los argumentos de sujeto, complemento directo y complemento indirecto.

- El verbo auxiliar no puede seleccionar adjuntos circunstanciales.

- El verbo auxiliado no se puede intercambiar por una estructura con valor de sintagma nominal.

- Los pronombres átonos pueden ubicarse antes o después de la perífrasis.

- En la transformación de la perífrasis a interrogativa del tipo ¿QUÉ...? no se puede separar la perífrasis ni elidir el auxiliado, que debe en todo caso ser sustituido por HACER.

- Las transformaciones a la voz pasiva no pueden afectar al verbo auxiliar.

- En la transformación a pasiva del auxiliado, su complemento directo pasa a ser sujeto del auxiliar.

- La conmutación a una estructura topicalizada con un relativo no es posible en las perífrasis. Para que sean aceptables se debe incorporar un verbo del tipo HACER.

Una vez aplicados los criterios se han considerado 37 perífrasis: 34 de ellas son inequívocamente reconocidas como tales en el capítulo 28 de la $N G L E$ : son las construidas con Acabar de, Acabar por, Acertar a, Acostumbrar a, Alcanzar a, Arrancarse a, Cesar de Comenzar a, Dar a, Dar por, Deber, deber de, Dejar de, Empezar a, Empezar por, Estar a punto de, Estar por, Estar para, Estar a punto de, Estar al, Haber de, Haber que, Hacer(se $)^{8}$, Ir a, Llegar a, Parar de, Pasar a, Poder, Ponerse a, Soler, Tardar en, Tener Que, Terminar de, Terminar por, Venir a y Volver a. Se han incluido tres que cumplen 6 o más de los criterios elegidos; se trata de Prestarse a (6 criterios), Caber ( 7 criterios) y TRATAR DE (8 criterios). Finalmente, destacaremos que no hemos consignado en nuestro corpus siete de las unidades consideradas perifrásticas en la gramática académica: ACERTAR A, Alcanzar a, Arrancarse a, Estar a punto de, Estar al, Estar para y Cesar de. Asimismo, DEBER DE apenas aparece en dos ocasiones y utilizada incorrectamente en lugar de la variante obligativa. Ante este hecho, se han revisados todos los usos de Deber y se ha confirmado que en todos ellos se percibe el valor obligativo propio de dichas perífrasis.

Las dificultades son aún mayores a la hora de identificar las perífrasis de participio. De hecho, no hay consenso entre los investigadores para decidir si existen las perífrasis de esta naturaleza. Los mayores problemas tienen que ver con las dificultades a la hora de distinguir entre las construcciones perifrásticas y las semicopulativas. En palabras de Garachana (2014:12):

Las perífrasis de participio plantean dificultades de adscripción al ámbito de las perífrasis verbales, dado el carácter predicativo del participio, equivalente a la función de los adjetivos en estructuras atributivas, con verbos (semi)copulativos. Esto es, en el terreno de las perífrasis verbales el límite entre las construcciones perifrásticas y las atributivas no está claro. Tanto es así que algunos autores dudan de la existencia de las perifrasis de

8 No se la incluye en el capítulo 28 , sino en el epígrafe 26.10o, donde se la clasifica como perífrasis causativa. 
participio. La Real Academia limita las perífrasis a las combinaciones con participio cuyos auxiliares son estar, tener y llevar. Otros autores admiten también los verbos encontrarse, hallarse, ir, quedar(se), resultar, salir, venir, verse, que la gramática académica considera dentro de las estructuras atributivas.

Ante tal estado de cosas, asumiremos la posición restrictiva de la Academia y consideraremos como perifrásticos solamente los verbos ESTAR, TENER y LLEVAR.

En lo referido a las perífrasis de gerundio la nómina está compuesta de 8 unidades consideradas inequívocamente como tales por la NGLE: ACABAR, Continuar, Estar, Ir, Llevar, Seguir, Pasar(se) y Venir. Dos de las incluidas en la $N G L E$ no aparecen utilizadas en nuestro corpus: ANDAR y COMENZAR.

A partir de la nómina identificada, nos fijaremos en primer lugar en el rendimiento de las perífrasis en relación con el resto de las predicaciones:

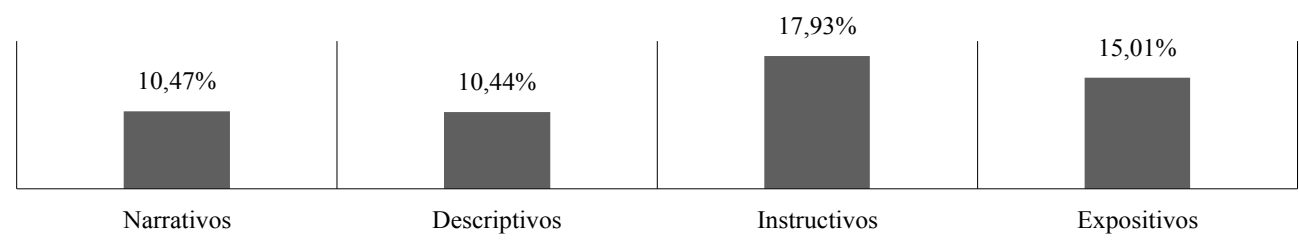

Cuadro 28. Rendimiento de las perífrasis.

El gráfico nos muestra cómo el rendimiento es mayor en el caso de los textos expositivos y, muy especialmente, de los instructivos, donde suponen casi un $18 \%$ del total de predicaciones verbales identificadas. En cambio, en los otros modos del discurso apenas representan un $10 \%$ del total. Las diferencias son aún más evidentes si desagregamos los datos según el tipo de perífrasis:

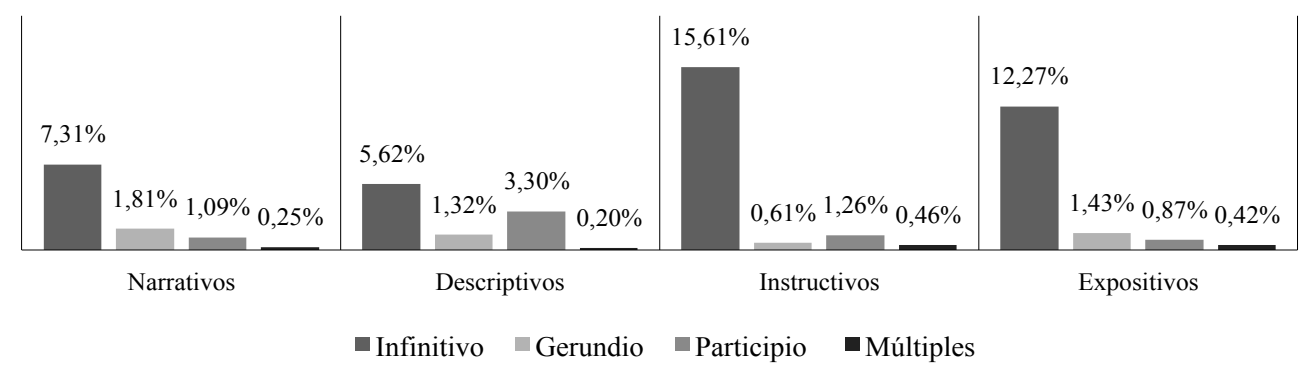

Cuadro 29. Perífrasis según su naturaleza formal.

Las perífrasis de participio tienen especial rendimiento en el texto descriptivo, como lo demuestra que su frecuencia de aparición casi triplica el promedio de uso en el corpus. Tal rendimiento parece asociado a una forma expresiva esencialmente estática. Lo confirmaría el hecho de que las perífrasis de participio con ESTAR superan el 3\% de del total de predicaciones verbales en los textos descriptivos. 
Las de gerundio son especialmente frecuentes en los textos narrativos. En ese sentido cabe destacar su relevancia en la construcción de las llamadas formas continuas de los verbos. Sin embargo, su presencia es mínima en los instructivos, donde apenas supera el 0,6\%.

En cuanto a las perífrasis múltiples, su rendimiento es cuantitativamente muy escaso pues solo suman el $0,3 \%$ de las predicaciones. No obstante, resulta razonablemente uniforme en los cuatro segmentos del corpus, de donde se deduce que es una construcción no dependiente de tal variable.

Aun cuando resulta claro que la perífrasis más habitual es la de infinitivo, con un uso que acumula de promedio casi el $11 \%$ de todas las identificadas, su rendimiento varía mucho según la naturaleza tipológica de los textos. Su uso es distintivo de los textos instructivos donde se acumula cerca del 16\% de las unidades consignadas; en segundo término, también es llamativo su uso por encima de la media en los enunciados expositivos. En cambio, en los descriptivos y narrativos oscila entre el 5\% y el 7\%. Es un rendimiento tres veces menor.

Ese mayor rendimiento en exposición e instrucción se asocia a una preferencia evidente por las perífrasis modales de obligación y posibilidad. Así se observa en el siguiente cuadro, en el que valoramos el uso de las perífrasis de infinitivo según su naturaleza. Son las más frecuentes en los cuatro modos del discurso, pero las diferencias son llamativas:

\begin{tabular}{|c|c|c|c|c|c|c|c|c|}
\hline & Obligación & Posibilidad & Durativa & Habitual & Incoativa & Ingresiva & Iterativa & Terminativa \\
\hline Narrativo & $1,84 \%$ & $3,69 \%$ & $0,06 \%$ & $0,22 \%$ & $1,13 \%$ & $0,31 \%$ & $0,13 \%$ & $0,16 \%$ \\
\hline Descriptivo & $0,93 \%$ & $2,50 \%$ & $0,10 \%$ & $0,80 \%$ & $0,52 \%$ & $0,49 \%$ & $0,11 \%$ & $0,52 \%$ \\
\hline Expositivo & $5,77 \%$ & $4,79 \%$ & $0,02 \%$ & $0,67 \%$ & $0,42 \%$ & $0,70 \%$ & $0,06 \%$ & $0,41 \%$ \\
\hline - Instructivo & $6,74 \%$ & $7,51 \%$ & $0,01 \%$ & $0,43 \%$ & $0,55 \%$ & $0,68 \%$ & $0,10 \%$ & $0,24 \%$ \\
\hline
\end{tabular}

Cuadro 30. Perífrasis de infinitivo.

\section{CONCLUSIÓN}

El trabajo realizado nos ha permitido perfilar de manera precisa cómo se articulan los enunciados en el texto escrito y cuáles son los rasgos distintivos en cuatro modos del discurso. Tal descripción se ha realizado sobre la base de tres variables, como son la extensión de los enunciados, su configuración sintáctica y la naturaleza de las predicaciones verbales utilizadas.

En el corpus analizado hemos identificado que el promedio de extensión de los enunciados se fija en torno a 17 palabras, y que el $90 \%$ de las unidades se mueven en una franja entre 6 y 30. Serán, por tanto, los límites de extensión habituales.

El $67 \%$ de los enunciados se construyen sintácticamente como oraciones compuestas, mientras que el 31,5\% responde a la estructura de una oración simple. Los grupos sintácticos no oracionales apenas dan cuenta del 1,5\% de las unidades analizadas. Tal hecho nos permite concluir que en el caso del texto escrito es plenamente acertada la correlación tradicionalmente establecida entre la unidad discusiva enunciado y la unidad formal oración. 
En los quince patrones sintácticos que hemos identificado, la coordinación tiene un rendimiento muy limitado. De hecho, el $84 \%$ de las unidades están constituidas por una oración simples o una compuesta; en un $6,22 \%$ se coordinan una oración compuesta y una o más simples; en un $5 \%$, dos simples; y en un $2,35 \%$, dos compuestas. Los diez patrones restantes apenas suman el 2\%. Debemos señalar, además, que la coordinación es esencialmente copulativa: tal relación agrupa un $78,5 \%$; en cambio la adversativa $(12,7 \%)$ y la disyuntiva $(8,8 \%)$ tienen un rendimiento mucho más limitado.

Dentro de los grupos no oracionales solo los sintagmas nominales superan el $1 \%$ de rendimiento: los preposicionales $\mathrm{y}$, muy especialmente, los adjetivos tienen una presencia testimonial en nuestro corpus. Sin embargo, cabe destacar que no es extraño que dentro de tales grupos se aloje una oración subordinada; lo demuestra el hecho de que así sucede en el $35 \%$ de los casos.

El rendimiento de la oración compuesta es claramente mayor que el de la simple, y dentro de ella se observa que el $50 \%$ de los casos incluye una sola predicación subordinada, en el $30 \%$, incorpora 2 y en el 13,5\% son tres. Las unidades con cuatro o más predicaciones suman algo menos del 7\%. Parece, pues, que el límite de complejidad se establece en tres predicaciones subordinadas, aunque se consignen casos de hasta siete. En la construcción sintáctica se evita ir más allá de dos niveles de incrustación oracional. Lo demuestra el hecho de que solo un $5,72 \%$ de las predicaciones verbales identificadas quedan fuera de tal tendencia. Hay, en cambio, una preferencia por un nivel uno o dos de incrustación, espacio en el que se suma casi el $62 \%$ de los casos. Un 32\% estaría en un nivel cero, pues correspondería a las predicaciones verbales en enunciados construidos sobre la base de oraciones simples.

Un $66 \%$ de las predicaciones verbales usadas son formas conjugadas. Por su parte, las formas no personales suman un $20 \%$; dentro de ellas, hay una apuesta decidida por las construcciones de infinitivo, que recogen el $82 \%$ de los casos, mientras que las de gerundio son residuales y apenas superan el 4\%. Por último, identificamos un 14\% de perífrasis verbales. De ellas, el 77\% son de infinitivo, mientras que las restantes se dividen a partes iguales entre las de gerundio y la de participio. Dentro de las perífrasis de infinitivo, comprobamos una preferencia evidente por las modales $(80 \%)$ frente a las aspectuales $(20 \%)$.

Hasta aquí los resultados entendidos de manera global; no obstante, cabe establecer diferencias importantes cuando se habla de los modos del discurso en los que hemos analizado cómo se construyen los enunciados textuales. Nos fijaremos ahora cuáles son los rasgos que en cada uno de ellos se apartan de las tendencias generales que hemos indicado.

Los enunciados expositivos parece que son los más sintácticamente más complejos. Como resultado de ello, hemos podido identificar algunos rasgos característicos. Así, es el contexto donde más se usan los grupos sintácticos no oracionales (específicamente, los sintagmas nominales), cuyo rendimiento triplica al observado en de cualquier otro contexto discursivo. Al mismo tiempo, se trata de los enunciados en lo que se acumulan más predicaciones subordinadas: los enunciados de tres o más suponen un $25 \%$ de las oraciones compuestas identificadas, mientras que en resto de modos nunca se supera el 14\%. Asimismo, exhiben la mayor predisposición a la inserción oracional subordinada. De hecho, el nivel tres se consigna en casi el $8 \%$ de los enunciados, cuando en el resto nunca supera el $4 \%$.

Por su parte, los enunciados correspondientes a textos descriptivos son normalmente los más cortos: el $80 \%$ tiene menos de 25 palabras y la franja de extensión más frecuente está 
entre 11 y 15 . Además, son los menos elaborados en términos sintácticos. Como resultado de ello, más del $40 \%$ se construye sobre la base de una oración simple, diez puntos por encima de la media; y a su vez, cuando son oraciones compuestas, tienden a incluir como mucho una subordinada. Como resultado, los enunciados con dos o más subordinadas no alcanzan el $40 \%$, mientras que en los otros tres modos del discurso se supera siempre el $45 \%$. Tal hecho lleva a que la incrustación oracional sea igualmente menor. El nivel 0 supone un $42 \%$ de los casos, cuando la media está en el 32\%. Todo ello tiene como efecto que solo en el $30 \%$ de los enunciados se identifique más de dos predicaciones verbales, mientras que en los otros tipos textuales suponen al menos el $40 \%$.

Las unidades correspondientes a los textos instructivos coinciden plenamente con las de los descriptivos en lo referido a su extensión. Sin embargo, hay algunos rasgos distintivos que conviene destacar. En primer lugar, es en ellas donde mayor rendimiento exhiben las predicaciones verbales que no se construyen como formas conjugadas: alcanzan algo más del $41 \%$ de los casos. Tal hecho es consecuencia de que las formas no personales sumen el $25 \%$, frente al $20 \%$ de media en el total del corpus. Dentro de ellas, el uso del infinitivo supone más del 90\%, diez puntos por encima del media; en cambio, las construcciones de gerundio y participio apenas se utilizan, como lo demuestra el hecho de que en ninguno de los dos casos el uso alcanza el 5\%. El segundo rasgo que debemos destacar es la distribución del uso de las coordinaciones: las copulativas son las más frecuentes, como en el resto del corpus; sin embargo, hay una inversión en la frecuencia de las adversativas y, muy especialmente, las disyuntivas. Las primeras se reducen al 9,5\% frente al $12,7 \%$ del total. Por su parte, las segundas reúnen casi el 18\% de los casos; en cambio, la frecuencia global en el corpus no llega al $9 \%$.

Por último, en lo que toca a los textos narrativos, debemos decir que su construcción refleja de forma muy equilibrada los resultados descubiertos para la globalidad del corpus. Solo cabe destacar alguna diferencia en el uso de las formas no personales, donde aumenta el uso de las construcciones de participio, un 33\% frente a un $14 \%$ en el total. Como resultado de ello, desciende más de $20 \%$ la frecuencia de aparición de construcciones de infinitivo, que se quedan en el $60 \%$.

\section{Referencias bibliográficas}

Anula, A. (2007). "Tipos de textos, complejidad lingüística y facilitación lectora”. En Roncero Mayor, L. (ed.). Actas del VI Congreso de Hispanistas de Asia. Monográficos Sinoele, 8, pp. 43-55.

Bustos Gisbert (2013a). "Grado de evidenciación de la conexión textual en escritos de naturaleza expositiva". Verba, 40, pp. 93-138.

Bustos Gisbert (2013b). Arquitextura. Salamanca: Ediciones Universidad de Salamanca.

Berko, J. y N. Bernstein (2001). Psicolingüística. Madrid: McGraw-Hill (texto original de 1999).

De Beaugrande, R. (1984). Text production. Norwood NJ: Ablex Publishing Corporation.

Fernández Martín, P. (2014). "Hacia un concepto cuantitativo del concepto de perífrasis verbal en español”. Lenguas Modernas, 44/2, pp. 31-54.

Ferrreiro, E. (1996). "Los límites del discurso: puntuación y organización textual”. En Ferreiro, E., C. Pontecorvo y otros (eds.). Caperucita Roja aprende a escribir. Madrid: Gedisa, pp. 129-161.

Figueras Coronilla, C. (1999). "La semántica procedimental de la puntuación”. Especulo, 12. www. ucm.es/info/especulo/numero12/puntuac.html (12-11-2016).

Figueras Solanilla, C. (2001). Pragmática de la puntuación. Barcelona: Octaedro. 
Fuentes Rodríguez, C. (2014). "Los límites del enunciado”. Estudios de Lingüistica del español, 35/1, pp. 137-160.

Gallardo Paúls, B. (2008). "Las huellas lingüísticas de la teoría de la mente: intersubjetividad y enunciación en el trastorno por déficit de atención/hiperactividad”. Revista de Neurología, 46/1, pp. 29-35.

Garachana Camarero, M. (2014). "Perífrasis verbal". En Grupo de innovación "Ciencias del lenguaje y docencia": Diccionari de Lingüistica. Barcelona, Universitat de Barcelona. http://www.ub.edu/ diccionarilinguistica/content/per\%C3\%ADfrasis-verbal (27-10-2016).

Gutiérrez Ordóñez, S. (1997). "Comentario sintáctico". En La oración y sus funciones. Madrid: Arco Libros, pp. 577-598.

Pastor Pérez, L1. (2008). Escritura sexy. Barcelona: Universitat Oberta de Catalunya.

Pinker, S. (1995). El instinto del lenguaje. Madrid: Alianza.

RAE (2009). Nueva Gramática de la Lengua Española. Madrid: Espasa.

RAE (2010). Ortografía de la lengua española. Madrid: Espasa.

Roselló Vereguer, J. (2010). Análisis de los signos de puntuación en textos de estudiantes de educación secundaria. Valencia: Universitat de València. Tesis doctoral. 